\title{
Physiological and Ethological Effects of Sativex, A Cannabis-based Medicine, Examined on Ants as Models
}

\section{Marie-Claire Cammaerts ${ }^{1 *}$ and Roger Cammaerts ${ }^{2}$}

${ }^{1}$ Independent Researcher, Retired from the Biology of Organisms Department, University of Brussels, Belgium

${ }^{2}$ Independent Researcher, Retired from the Natural and Agricultural

Environmental Studies Department (DEMNA) of the Walloon Region, Belgium

*Corresponding Author: Marie-Claire Cammaerts, Independent Researcher, Retired

from the Biology of Organisms Department, University of Brussels, Belgium.

DOI: 10.31080 /ASPS.2020.04.0568
Received: May 23, 2020

Published: July 28, 2020

(C) All rights are reserved by Marie-Claire

Cammaerts and Roger Cammaerts.

\section{Abstract}

Sativex is a cannabis-based medicine chiefly used for treating persons suffering from multiple sclerosis. One of the qualities expected for this drug is pain easing. Using ants as models, we found that this medicine reduces their tactile perception (which is linked to pain perception), but also that it negatively affects their orientation ability, social relationships, cognition, learning and memory. It leads to no habituation, but to no adaptation, and to some dependence. Sativex becomes less efficient 8 hours after weaning, its effect completely vanishing in 12 - 14 hours. The small amount of ethanol contained in Sativex only somewhat decreases pain perception and memory, and do not lead to dependence. The observation of adverse effects on ants used as a model should warn practitioners that attention should be paid to persons treated with Sativex, i.e. by monitoring their behavior, social relationships, cognition, memory, and by watching for mental and orientation impairments which may present a danger when risky activities are concerned. Keywords: Cognition; Dependence; Memory; Multiple Sclerosis; Myrmica sabuleti; Social Relationship

\section{Abbreviations}

ang.deg.:Angular Degrees; ang.deg./cm:Angular Degrees Per cm; $\mathrm{mm} / \mathrm{s}$ :Millimeter per Second; $\chi^{2}$ :Chi-Square; vs:Versus; $\mathrm{n}^{\circ}$ :Number; cm:Centimeter; mm:Millimeter; mL:Milliliter; $\mu$ L:Microliter; ng:Nanogram; mg:Milligram; kg:Kilogram; s:Second; min:Minute; h:Hour; t:Time; \%:Percentage

\section{Introduction}

To relieve pain, drugs reducing its perception are commonly prescribed, and recently, for relieving pain associated to multiple sclerosis and spasticity, an extract of cannabis marketed under the brand name Sative ${ }^{\circledR}$ has been authorized as a medicine. Due to its novelty, few is known about the consequences of such a use. Being accustomed to examine on ants as models the effects of products used by humans (36 products have already been investigated, e.g. in [1-3]), we intended here to examine the side effects of Sativex ${ }^{\circledR}$.
Also known under the non-proprietary name nabiximols, Sativex $^{\circledR}$ (GW Pharma Ltd) is a medicine made of extracts of leaves and flowers of the plant Cannabis sativa L. It contains a ca 1:1 mixture of delta-9-tetrahydrocannabinol (THC) and cannabidiol (CBD), two major active substances of the plant (their chemical structure is shown in figure 1). Sativex contains also ethanol, a major excipient the effect of which will also be taken into account in our experimental investigation.

Here below, we first explain why using ants as models is a valuable choice, and then report what we need to know about the effects of Sativex. We state that it was only after completion of the experiments on ants we made with that medicine that we took full knowledge of its side effects through literature. 
Why choosing ants as models?

Most of the biological processes (e.g. metabolism, nervous cells functioning) are similar for all animals, including humans.Several vertebrates and invertebrates are thus commonly used as models [4], for instance rats, monkeys, the mollusk Aplysia californica, the beetle Tribolium castaneum, the fruit fly Drosophila melanogaster, and the domestic bee Apis mellifera [5,6]. Ants can also be used. Colonies containing hundreds or thousands of ants can be easily maintained in laboratories, at low cost. They are among the most evolved hymenoptera, as for their anatomy, physiology and ethology, presenting among others a division of labor and a social regulation, marking differently their foraging area, nest entrance and inside of the nest, recruiting congeners, navigating using visual and olfactory cues, managing cemeteries, having some valuable numerosity abilities, etc [7-9]. It looks thus reasonable to use the ant Myrmica sabuleti, Meinert, 1861, from which many biological aspects are well known, as a model for examining the physiological and ethological effects of substances employed by humans.

\section{Some information about the action and effects of Sativex}

\section{Efficiency}

Sativex is primarily delivered to persons suffering from multiple sclerosis, with the aim of improving spasticity and relieving associated pain. The psychoactive THC cannabinoid contained in this medicine accounts for its therapeutic analgesic effect, but also for some of its adverse effects such as sedation. TCH acts as a partial agonist of cannabinoid receptors, mainly CB1, which are most densely located in the central nervous system, especially in areas accounting for nociception and short-term memory. THC not only modulates pain perception, but also acts on spasticity as a muscle-relaxant by reducing the amount of released glutamate neurotransmitters $[10,11]$. CBD is a non-psychoactive cannabinoid with no agonist action on the CB receptors [12]. It modulates the metabolism of THC by blocking its conversion to the more psychoactive metabolite 11-hydroxy-THC [10]. However, due to its association with TCH in the Sativex medicine, it is currently difficult to attribute other distinct therapeutic properties to CBD [12], but at therapeutic doses, the pharmacodynamic safety profile of Sativex is comparable to that of THC alone [13].

Clinical randomized and controlled trials in patients under Sativex $v s$ placebo showed a statistically significant reduction of spasticity [14]. However, another clinical trial showed a lack of sta- tistically significant efficiency for the change in spasticity severity score [15]. Nevertheless, lengthening of the time to treatment failure in spasticity was found significant under Sativex medication, failure being experienced in $44 \%$ of the Sativex patients against $94 \%$ for those under placebo [16]. Compared in a clinical test to Baclofen, another medicine used for reducing spasticity, Sativex showed a consistently improvement in a timed 10-meter walk test and an improvement in gait parameters [17]. Injected in mice impaired by spasticity, Sativex was found as effective as Baclofen, with a $40 \%$ peak reduction in spasticity [18].

Compared to placebo, Sativex showed not only a significant reduction of spasticity, but also an improvement of the quality of sleep [19]. An observational study on the effect of Sativex, conducted in routine care of 335 patients with a follow-up period of $3-4$ months, also allowed concluding to a significant relief of spasticity and related sleep disturbances in patients suffering from multiple sclerosis [20].

Clinical subjective scales showed greater reduction of pain intensity in pain-complaining multiple sclerosis patients receiving Sativex than in pain-free multiple sclerosis control patients [21]. In a clinical randomized trial $v s$ placebo, Sativex was significantly efficient as an antispasticity treatment and for relieving related pain [22]. Moreover, when Sativex was used as a treatment for pain caused by rheumatoid arthritis, a significant reduction of pain at rest and on movement as well as a better quality of sleep was observed [23]. Sativex was also found to significantly reduce neuropathic pain characterized by allodynia [24]. However, used in advanced cancer patients with chronic pain unalleviated by the use of opioids, Sativex did not prove to be superior to placebo for improving the average pain numerical rating scale, but showed benefits for some secondary points such as worst pain score and sleep disruption [25].

Searching more objective tools than ordinary clinical assessments, Russo et al. used an extensive neurophysiological assessment of sensory-motor circuits [26]. They showed that Sativex can be effective in reducing spasticity and associated symptoms by increasing intracortical inhibition and reducing spinal excitability.

\section{Safety, adverse effects and adaptation}

Clinical studies point out some adverse effects of Sativex use. 
In an open-label trial on 137 patients suffering from multiple sclerosis, 292 unwanted effects were reported, among them, dizziness in $14.6 \%$ of the patients, fatigue in $6.6 \%$ and weight loss in $5.1 \%$ of them. Only $2.2 \%$ of the patients suffered from serious adverse events: 2 cases of seizure, one of vomiting, one of impaired balance and a case of diarrhea [27]. In randomized-controlled clinical trials of more than six hundred patients, the most adverse reactions to Sativex use were dizziness (in 27.6\% of the cases) and fatigue (9.2\%) [28]. Adverse effects on 805 patients under Sativex treatment, summarized by Robson and listed in the product characteristics published by the manufacturer GW Pharma, concerned dizziness (25\%), fatigue (12.5\%) and sleepiness (8.2\%), but also in a lesser proportion, disorientation (4.1\%), attention disturbance $(3.9 \%)$, feeling drunk (3\%), dissociation (1.7\%), memory impairment (1.4\%) and even paranoia (0.5\%) and suicidal ideation (0.5\%). In comparison, 741 placebo patients showed respectively $8.2,8.4,2.3,0.8,0.1,0.4,0.1,0.1,0.1$ and $0.1 \%$ of these adverse effects $[29,30]$.

However, in an observational study based on 325 patients, only $1.2 \%$ cases of adverse drug reaction to Sativex medication were reported, among them, despondency, fatigue, weakness, worsened walking ability, dizziness, headache, and muscle spasm. The authors concluded that Sativex is a well-tolerant option for resistant multiple sclerosis spasticity in clinical practice [20]. A study examining the potential negative effects of a Sativex long-term treatment on cognition and mood of about sixty patients found no association with this medicine [31]. Another study on about sixty patients found no significant effect of Sativex on cognitive and neurobehavioral functions, but its authors advised the relevance of an extensive neuropsychological evaluation in multiple sclerosis patients [32]. Indeed, the same laboratory warned for possible but rare neurobehavioral side effects of Sativex such as suicidal ideation [33]. A randomized, placebo-controlled clinical trial with Sativex used for treating patients suffering from Huntington's disease, allowed concluding that this medicine was well-tolerated, with no significant differences on motor, cognitive, behavioral and functional scores [34]. The use of Sativex for reducing pain due to rheumatoid arthritis [23] and for reducing spasticity and associated pain [22] leaded to only mild or moderate adverse events, if any.

Weight loss and less food consumption were demonstrated in toxicological studies on rats fed with very high Sativex doses (50 - $100 \mathrm{mg} / \mathrm{kg} /$ day). They presented significant weight loss and less food consumption although not in a dosage-related manner, while gestating rats presented these symptoms in a dose-related manner when fed with doses of $5-25 \mathrm{mg} / \mathrm{kg} /$ day. Dogs also suffered from less food consumption and weight loss when fed with high doses of Sativex (100 - $200 \mathrm{mg} / \mathrm{kg} /$ day). Gestating rabbits fed with 5 $25 \mathrm{mg} / \mathrm{kg} /$ day Sativex dose experienced same reductions in body weight and food consumption. However, these doses exceed the maximum daily dose of $1 \mathrm{mg} / \mathrm{kg} /$ day recommended for humans by the manufacturer GW Pharma 2019 [30].

\section{Habituation to and dependence on Sativex}

No dose escalation (habituation) or toxicity was reported after 52 weeks of Sativex use in order to relieve neuropathic pain characterized by allodynia [24] and in a 82 weeks follow-up of patients suffering from multiple sclerosis and spasticity, the patients even tended to diminish their self-titrated daily dose in the course of their treatment [27].

To check physiological and psychological dependence, 25 out of 137 patients voluntary experienced a sudden weaning of Sativex, resulting for 11 of them in only slight adverse syndromes. In most of them, multiple sclerosis symptoms returned 5 - 10 days after weaning and 22 patients resumed their Sativex treatment within two weeks after weaning, showing dependence and suggesting that the benefits of the treatment were not due to a placebo effect [27].

In a randomized double-blind study, the abuse potential of the content of 8 Sativex sprays (the quantity used in the present experimental work on ants) measured using an addiction score was not different from placebo and, as measured by drug-liking and subjective drug value scores, not significantly different than by using only an equivalent quantity of synthetic THC. On secondary measures such as ARCI addiction to Marijuana and LSD scales, Sativex produced significantly lower scores than THC alone, the latter substance (dronabinol) being known for having some abuse potential [35]. According to an expert advice, dependence on Sativex and its abuse is thus likely to occur in only a very small proportion of patients [29].

\section{Pharmacokinetics}

Apparent elimination half-life of Sativex in human blood plasma corresponding to a single dose of 8 oromucosal sprays is 5.25 (SD = 3.43) h for THC and 9.36 (6.81) h for CBD. The concentration level declines sharply after a first maximum occurring at $\mathrm{t}=\mathrm{ca} 1 \mathrm{~h}$ and presents a second peak around $t=6 \mathrm{~h}$ [36]. Thereafter, being highly soluble in lipids, THC/CBD is gradually released in the plasma from 
fatty tissues, what explains that the terminal half-life lasts at least one week [37].There is no evidence of THC/CBD accumulation on repeated dosing [36].

The single dose of 8 oromucosal sprays gives a maximum measured THC plasma concentration of $5.4 \mathrm{ng} / \mathrm{mL}$ reached in $1 \mathrm{~h}$, compared to at least $150 \mathrm{ng} / \mathrm{mL}$ reached in only $9 \mathrm{~min}$ for smoked cannabis [38]. The small amount of THC released by using Sativex oromucosal sprays, its slower delivery rate in blood and its lengthened decrease after weaning could be the reason for no significant abuse (addiction) reported with this medicine [36].

\section{Aim of the Study}

According to the fact that many studies on the effects of Sativex were funded or sponsored by its manufacturer, it was not uninteresting to examine several physiological and ethological effects of this medicine, being blind to the situation. In this work, we considered the potential impact of Sativex and of the amount of ethanol it contains on ants' activity, food consumption, locomotion, audacity, tactile (pain) perception, brood caring and aggressiveness against nestmates (i.e. social relationships), cognition, learning and memory, adaptation to side effects, habituation to the wanted effect, and dependence on the drug consumption. We also evaluated the duration of the effect of Sativex and ethanol on ants after their consumption was stopped.

Here below, we first explain our materials and methods. As the protocols were similar to those employed for examining the effects of until now 36 products used by humans, e.g. in [1-3], we shortened their description and tried to avoid self-plagiarism. We then related and discuss our results first on Sativex then on only the ethanol it contains. Finally, we compare our findings to those of the literature and conclude.

\section{Materials and Methods}

\section{Collection and maintenance of ants}

The experiments were conducted on two colonies of $M$. sabuleti collected in September 2019 in an abandoned quarry located at Olloy/Viroin (Ardenne, Belgium). These colonies were nesting in grass and under stones. They contained about 500-700 workers, a queen and brood. Each colony was maintained in the laboratory in one to three glass tubes half filled with water, a cotton plug separating the ants from the water. The nest tubes of each colony were deposited in a tray $(34 \mathrm{~cm} \times 23 \mathrm{~cm} \times 4 \mathrm{~cm})$ which served as a foraging area. In this area, pieces of Tenebrio molitor larvae (Linnaeus, 1758) were deposited three times per week on a glass piece, and a $30 \%$ sugar solution in a water was permanently provided in a cotton plugged tube. The lighting equaled about 330 lux while working on ants. The ambient temperature was permanently $c a$ $20^{\circ} \mathrm{C}$, the humidity $\mathrm{ca} 80 \%$ and the electromagnetism $2 \mu \mathrm{Wm}^{2}$. Such conditions were suitable for the species. The ants are here often named workers or nestmates as commonly do researchers on social insects.

\section{Solution of Sativex and of ethanol given to the ants}

A package of Sativex ${ }^{\circledR}$ (GW Pharma Ltd, Cambridge, UK) was furnished by the pharmacist Wera (Brussels, Belgium). This drug is delivered in the form of sprays. Each spray delivers $100 \mu \mathrm{l}$ of a solution containing $2.7 \mathrm{mg}$ delta-9-tetrahydrocannabinol (THC) and $2.5 \mathrm{mg}$ cannabidiol (CBD), $50 \mu \mathrm{l}$ of ethanol (an excipient with a recognized effect), as well as propylene glycol (a food additive) and peppermint oil.

Advised to take 2 to 12 sprays per day of Sativex, humans commonly take 8 of these doses. Moreover, humans consume about one liter of water per day. Insects, and consequently ants, drink proportionally about ten less water than mammals. Therefore, a solution of the content of 8 sprays of Sativex into $100 \mathrm{ml}$ water was used for maintaining ants under a Sativex 'diet' similar to that daily got by humans. To make it possible to be consumed by the ants, the content of 4 sprays was dissolved into $50 \mathrm{~mL}$ of the sugar water commonly drunk by the ants and the solution was provided in the ants' usual sugar water cotton plugged small tubes (Figure 1, lower part). It was checked each day if ants effectively drunk the provided solution of Sativex, what they did. The cotton plug of these tubes was refreshed each 2-3 days, and the entire solution was renewed each 7 days. The experiments made under Sativex diet started after the ants had been provided with this solution since 24 hours. The drug itself contains also about $50 \% \mathrm{v} / \mathrm{v}$ of ethanol. This is why, two days after the end of the experiments on ants under a Sativex diet, when the ants were no longer under the influence of this drug, the same experiments on the same colonies were made, this time under a diet with an ethanol quantity corresponding to 4 sprays into $50 \mathrm{ml}$ sugar water, thus made of $200 \mu \mathrm{l}$ of ethanol into $50 \mathrm{~mL}$ of the ants' usual liquid food and furnished to the ants exactly as was the Sativex solution. This allowed knowing if some of the effects observed on ants consuming Sativex may be due to or increased by the amount of ethanol contained in the medicine. This second series of experiments also allowed examining if ants could recover after having consumed Sativex. Thus, all the experiments were first performed on ants under normal diet, then on ants under a diet containing Sativex, and finally on ants under a diet containing ethanol. 

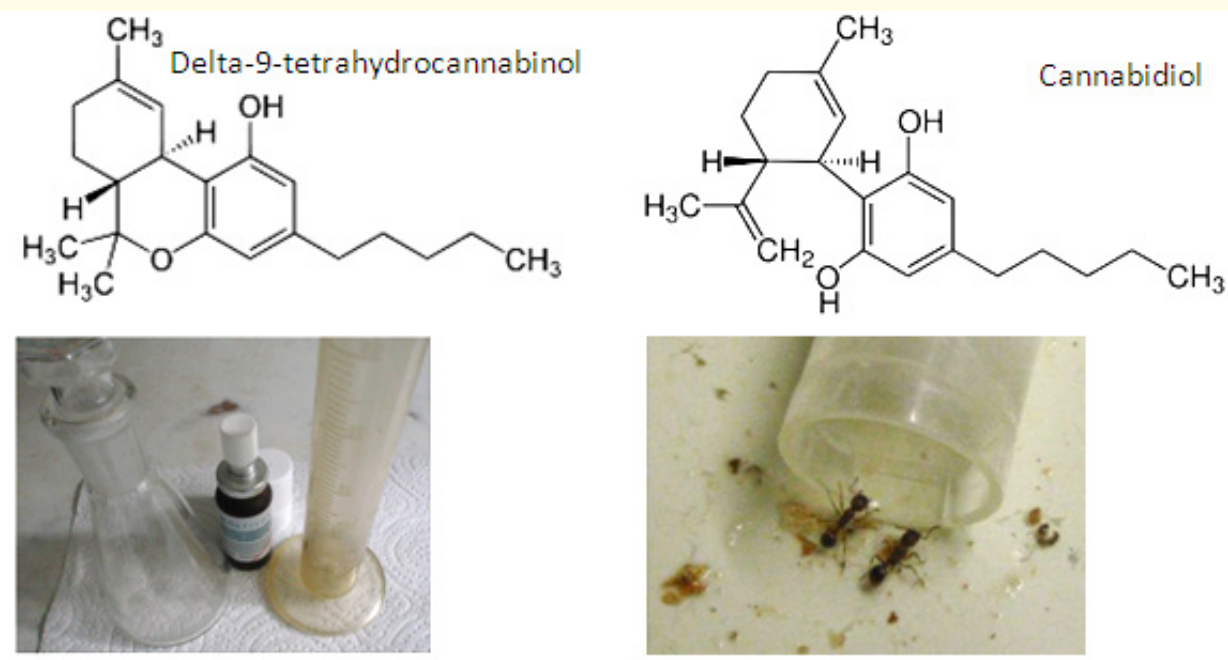

Figure 1: Upper part: chemical structure of the two active substances of the Sativex medicine. Lower part: instruments for making the Sativex solution given to the ants, and two ants drinking that solution.

Sugar water and meat food consumption, general activity

Each day, during six days, for each kind of diet (normal, with Sativex, with ethanol), the ants being active at any place of their environment (on their foraging area, nest entrance and inside the nest), those present on the meat food, and in or at the entrance of the sugar water tube were counted four times (three times during the day and one time during the night, each day at the same times o'clock) for each of the two used colonies and the mean of these eight daily counts was established for each kind of activity (general activity, eating, drinking) and diet (normal, Sativex, ethanol) (Table 1 , second line). The means of these six daily means were also established (Table 1, last line).

For each kind of ants' activity (general, eating or drinking), the effects of the different diets (normal, with Sativex, with ethanol), assessed thanks to six daily means, were compared to one another by using the non-parametric test of Wilcoxon [39], the level of probability being set at 0.05 .

\section{Linear and angular speeds; orientation to a tied nestmate}

These traits were assessed on ants freely moving in their foraging area, the speeds without stimulating the ants and the orientation while stimulating them with a nestmate tied to a piece of paper (Figure 2A). The tied nestmate emitted its mandibular glands attractive alarm pheromone [1-3]. To quantify the ants' speeds on one hand and their orientation on the other hand, we recorded the trajectory of 40 workers. These trajectories were analyzed using appropriate software [40] according to the following definitions. The linear speed (in mm/s) is the length of a trajectory divided by the time spent to travel it; the angular speed (in angular degrees/cm = ang.deg./cm) is the sum of the angles made by successive adjacent segments, divided by the length of the trajectory; the orientation (in ang. deg.) towards a location is the sum of successive angles made by the direction to the location and the direction of the trajectory, divided by the number of angles measured. When the mean angle value is lower than $90^{\circ}$, the animal tends to orient itself towards the location; when the value is larger than $90^{\circ}$, it tends to avoid the location [40]. The median and quartiles of each distribution of 40 values were established. The distributions obtained for ants under normal diet were compared to the corresponding distributions obtained for ants under a diet with Sativex and a diet with ethanol, using the non-parametric $\chi^{2}$ test [39].

\section{Audacity}

A cylindrical tower (height $=4 \mathrm{~cm}$; diameter $=1.5 \mathrm{~cm}$ ) attached to a squared platform $\left(9 \mathrm{~cm}^{2}\right)$, the entire apparatus being made of white Steinbach ${ }^{\circledR}$ paper, was deposited in the ants' tray, and the ants present on this apparatus, at any place, were counted 10 times over 10 minutes (Figure 2B) [12-14]. The numbers obtained for 
the two colonies were added, and the mean and extremes of the recorded numbers were established. For statistical purpose, the numbers obtained during two successive minutes were added. This provided five summed values. Those obtained for ants under normal diet were compared to those obtained for ants under a Sativex diet and for ants under an ethanol diet, using the nonparametric test of Wilcoxon [39].

\section{Tactile (pain) perception}

The ants perceiving the uncomfortable character of a rough substrate walk on it slowly, sinuously, and with difficulties (Figure 2C). An ant weakly perceiving the uncomfortable character of a substrate walks on it more quickly and less sinuously. To assess the ants' tactile perception, a folded piece $(3 \mathrm{~cm} \mathrm{x} 2+7+2=11 \mathrm{~cm})$ of emery paper $\mathrm{n}^{\circ} 280$ was tied to the bottom and the borders of a tray $(15 \mathrm{~cm} \times 7 \mathrm{~cm} \times 4.5 \mathrm{~cm})$. The tray presented a first $3 \mathrm{~cm}$ long zone, a second $3 \mathrm{~cm}$ long zone with the emery paper, and a last $9 \mathrm{~cm}$ long zone [1-3]. Such an apparatus was constructed for each colony. To make an experiment, 12 ants of each colony were deposited in the first zone of their own apparatus, and the trajectory of $12 \times 2$ ants walking on the emery paper was recorded. These ants' linear and angular speeds could then be quantified as described in the section 'Linear and angular speeds; orientation to a tied nestmate'. The median and quartiles of the obtained distributions of values were established, and the distributions obtained for ants under normal diet were compared to those obtained for ants under a Sativex and an ethanol diet using the non-parametric $\chi^{2}$ test [39].

\section{Brood caring behavior}

For each colony, a few larvae were removed from the inside of the nest and deposited on the foraging area, near the entrance. Five of these larvae were observed during six minutes (Figure 2D). The larvae among these 5 ones which were not re-entered inside the nest after 1, 2, 3, 4, 5, then 6 minutes were counted. The numbers obtained for the two colonies were added, and these six summed values corresponding to ants under normal diet were compared to the six values corresponding to ants under a diet with Sativex as well as to ants under a diet with ethanol using the non-parametric test of Wilcoxon [39].

\section{Aggressiveness against nestmates}

The potential aggressiveness against nestmates was quantified during five dyadic encounters of ants of each of the two colonies (a total of 10 encountering experiments). Each of these encountering was performed in a small cylindrical cup (diameter $=2 \mathrm{~cm}$, height
$=1.6 \mathrm{~cm}$ ), the borders of which had been slightly covered with talc to prevent escaping. During each encountering, one ant of the pair was observed for $5 \mathrm{~min}$ and its behavior towards the other ant was characterized by the numbers of times it did nothing (level 0 of aggressiveness), touched the other ant with its antennae (level 1), opened its mandibles (level 2), gripped and/or pulled the other ant (level 3), tried to sting or stung the other ant (level 4) (Figure 2E). The numbers of these different behaviors obtained for each two colonies were added (Table 3), and the sums relative to ants under a Sativex diet as well and those relative to ants under an ethanol diet were compared to those relative to ants under normal diet using the non-parametric $\chi^{2}$ test [39]. The ants' potential aggressiveness was also evaluated thanks to a variable 'a', which was the number of recorded aggressiveness levels $2+3+4$ divided by the number of recorded levels $0+1$.

\section{Escaping from an enclosure}

For each colony, six ants were enclosed under a reversed polyacetate cup $(\mathrm{h}=8 \mathrm{~cm}$, bottom diameter $=7 \mathrm{~cm}$, ceiling diameter $=$ $5 \mathrm{~cm}$ ) set on the ants' foraging area. They were introduced into this enclosure through a hole (diameter $=3 \mathrm{~mm}$ ) made in the ceiling of the glass. The lower part of the inner surface of the glass had been slightly covered with talc to prevent the ants climbing on it. A small notch ( $3 \mathrm{~mm}$ height, $2 \mathrm{~mm}$ broad) had been made in the rim of the bottom of the cup for allowing the ants escaping from the enclosure. To assess the ants' escaping ability, those still under the cup and those escaped after 2, 4, 6, 8, 10 and 12 min were counted. The results obtained for the two colonies were added (Table 3 ) and the six sums obtained for ants consuming Sativex, and well as those obtained for ants consuming ethanol were compared to those obtained for ants living under normal diet, using the non-parametric Wilcoxon test [39].

\section{Cognition}

For each colony, this trait was assessed as follows by setting 15 ants in an own separate apparatus. This apparatus consisted in a tray $(15 \mathrm{~cm} \times 7 \mathrm{~cm} \times 4.5 \mathrm{~cm}$ ) inside of which two duly folded pieces of white extra strong paper (Steinbach ${ }^{\circledR}, 12 \mathrm{~cm} \times 4.5 \mathrm{~cm}$ ) were inserted in order to create a way with twists and turns between a small area $2 \mathrm{~cm}$ long and a larger one $8 \mathrm{~cm}$ long, the latter beyond the difficult path. The ants were set all together in the small area. Then, the ants still in this area and those having reached the large area beyond the difficult path were counted after 2, 4, 6, 8, 10 and 12 minutes. The numbers obtained for the two colonies were added (Table 3) and the sums obtained for ants consuming Sativex, as 
well as those obtained for ants consuming ethanol, were statistically compared to those obtained for these ants under normal diet, using the non-parametric Wilcoxon test [39].

\section{Visual conditioning and memory}

At a recorded time, for each colony, a green hollow cube for ants consuming Sativex, and a yellow hollow cube for ants consuming ethanol, was set above the entrance of the sugar water tube aside the pieces of T. molitor larvae. The ants foraging or going to their food site underwent then visual operant conditioning. The hollow cube under which ants could move was made of strong green paper (Canson ${ }^{\circledR}$ ). The wavelengths reflection of the green and the yellow paper had been determined [41]. From the time of the deposit of the cube, the ants were tested first while they were expected to acquire conditioning, then, after having removed the cube, while they were expected to partly lose their conditioning. Ten ants of each colony were individually tested in a Y-apparatus devoted to their own colony. Each apparatus was made of strong white paper, and set outside the ants' foraging area, in a tray $(30 \mathrm{~cm} \mathrm{x} 15 \mathrm{~cm} \times$ $4 \mathrm{~cm}$ ) devoted to testing. The sides of each apparatus were slightly covered with talc to present escaping, and their floor was covered with a thin paper changed between each test. Each Y-apparatus was provided with a hollow cube in one of its branch, half of the tests being performed with the cube in the left branch and the other half of the tests with the cube in the right branch. An ant's choice of the branch containing the cube was considered as being a 'correct' response (Figure $2 \mathrm{H}$ ). Control experiments had been previously made on ants under normal diet [42]. Indeed, if the control experiences would have been done in the course of the present work, the ants would have been conditioned and consequently no longer naïve as for the presented conditional stimulus. For making a test on a colony, 10 ants were one after the other transferred into a Y-apparatus, in the part preceding its two branches. Each ant was observed until it turned either into the left or into the right branch of the Y-apparatus. Only the ant's first choice was recorded, and the choice was considered as valid when the ant was beyond a pencildrawn line indicating the entrance of the chosen branch (Figure $2 \mathrm{H})$. After having been so tested, the ant was transferred into a polyacetate cup until 10 ants of its colony were tested, in order to not testing twice the same ant. After ten ants have been tested, they were transferred into their foraging area, near their nest entrance. For each test, the numbers of ants of the two colonies ( $n=10$ ants $\mathrm{x} 2$ colonies $=20$ responses) which gave the correct response were recorded, what allowed calculating the ants' conditioning score, i.e. the proportion of correct responses (Table 4). The successive numbers of correct responses obtained over time for ants consuming Sativex, as well as for ants consuming ethanol, were statistically compared to those previously obtained for ants living under normal diet using the non-parametric Wilcoxon test [39].

\section{Adaptation (tolerance) to Sativex adverse effects}

Individuals' adaptation to a drug consumption occurs when the adverse effects of this substance becomes weaker and weaker over its consumption. To examine such an adaptation occurrence, a trait impacted by the drug must be assessed again after several days of its consumption. In the present work, as for Sativex, the ants' orientation to a tied nestmate (impacted by the drug, see the subsection relative to orientation) was again assessed after 13 days of Sativex consumption, exactly as it had been assessed after one day of consumption, and the results obtained after 13 and one days were compared to one another using the non-parametric $\chi^{2}$ test [39].

\section{Habituation to Sativex or to ethanol wanted effects}

Individuals' habituation to a drug occurs when its beneficial effect decreases over its consumption. For Sativex, one of the wanted beneficial effects we can observe on ants is the reduction of pain perception. Therefore, we again assessed the ants' linear and angular speeds on a rough substrate after 14 days of Sativex consumption, just like they had been assessed after four days of consumption, and the results obtained after 14 and 4 days of consumption were compared to one another using the nonparametric $\chi^{2}$ test [39]. As for ethanol, we again assessed the ants' angular speed on a rough substrate after 14 days of its consumption and compared the results to those obtained after four days of consumption.

\section{Dependence on Sativex or ethanol consumption}

Individuals consuming a given substance, e.g. a drug become dependent on this substance when they continuously want it and prefer food containing it to food free of it. In the present work, dependence was examined after the ants consumed Sativex, as well as ethanol since 15 days. For each colony, 15 ants under Sativex or ethanol diet were deposited in a tray $(15 \mathrm{~cm} \times 7 \mathrm{~cm} \times 5 \mathrm{~cm})$ which contained two cotton plugged tubes $(\mathrm{h}=2.5 \mathrm{~cm}$, diam. $=0.5 \mathrm{~cm})$, one filled with sugar water, the other filled with a sugar solution of Sativex or of ethanol similar to the one they consumed since 14 days. The tube containing the studied product was located on the right in the tray of colony $\mathrm{A}$, and on the left in the tray of colony $B$ (Figure 2I). The ants coming at the entrance of each tube were 
counted 15 times over 15 minutes. For each tube, the 15 counts were summed, and the summed counts obtained for the two colonies were added. The obtained sums (one for each tube) were compared to those expected if the ants randomly went onto the two tube entrances, using the non-parametric $\chi^{2}$ goodness-of-fit test [39].

Decrease of the effects of Sativex or ethanol after their consumption was stopped

This was studied after the ants had consumed either Sativex or ethanol during 16 days. The experimental protocol was similar to those previously employed, e.g. in [1-3]. The ants received a fresh solution of Sativex or ethanol 12 hours before weaning. After these 12 hours, the ants' linear and angular speeds on a rough substrate for Sativex, or only the ants' angular speed on this substrate for ethanol, were assessed as explained in the subsection relative to the ants' linear and angular speeds. Just thereafter (i.e. at $\mathrm{t}=0 \mathrm{~h}$ ), weaning started: the Sativex or the ethanol solutions were replaced by the usual sugar water. From this time, the ants' linear and angular speeds for Sativex, or only the angular speed on a rough substrate for ethanol, were assessed each two hours until they became similar to those the ants presented under normal diet (i.e. the control). The results were expressed by their median and quartiles in Tables 6 and 7 and are illustrated in Figure 3. The statistical comparisons of the locomotion values obtained in the course of time after weaning with those obtained just before weaning as well as with those of ants under a normal sugar water diet were done using the nonparametric $\chi^{2}$ test for independent samples [39] and looking up in a detailed table [43]. The resulting $\mathrm{P}$ values were checked for a possible adjustment using the Benjamini-Hochberg procedure for multiple testing [44] after choosing a false discovery rate (FDR) of 0.05 . The decrease over time of the effects of the Sativex and ethanol diets was traced, and its relevant function was determined using Statistica v.10 software.

\section{Results and Discussion}

\section{Impact of Sativex consumption}

General activity, sugar water and meat food consumption

Numerical results are given in Table 1. Compared with ants under a normal diet, those under Sativex diet were significantly less active $(\mathrm{N}=6, \mathrm{~T}=-21, \mathrm{P}=0.016)$. Also, they considerably consumed less meat than when living under normal $\operatorname{diet}(\mathrm{N}=6, \mathrm{~T}=-21, \mathrm{P}=$ $0.016)$. As for the consumption of sugar water, there was statistically no overall difference between ants under normal or Sativex
$\operatorname{diet}(\mathrm{N}=5, \mathrm{~T}=+5,-10, \mathrm{P}=0.313)$, but this resulted from the value obtained during the first day of Sativex consumption. Therefore, it may be presumed that Sativex reduced also the ants' sugar water consumption, but with some delay after an initial burst (statistical result without day $1: \mathrm{N}=4, \mathrm{~T}=10, \mathrm{P}=0.063$ ). These physiological impacts of Sativex are not in favor of its use. They agree with the mention of fatigue and weight loss in humans [27,28], with the reduction in food consumption and body weight observed in toxicology studies on rats, dogs and rabbits [30] and with side effects on humans reported in the instructions for use joined to the Sativex package: tiredness, food intake problems and anorexia.

\section{Linear and angular speeds}

Sativex consumption did not impact the ants' locomotion (Table 2 , lines 1,2), their linear and angular speeds being similar to those they presented while living under normal diet (linear speed: $\chi^{2}=$ $0.26, \mathrm{df}=3,0.95<\mathrm{P}<0.98$; angular speed: $\chi^{2}=1.52, \mathrm{df}=3,0.50<\mathrm{P}$ $<0.70$ ). However, before concluding, the influence of ethanol on the ants' locomotion has to be examined (see the subsection relative to ethanol, linear and angular speeds).

\section{Orientation}

This trait was largely affected by Sativex consumption (Table 2 , line 3). While ants living under normal diet fairly well oriented themselves towards a tied nestmate, they did so less well when consuming Sativex (Figure 2A1 and 2A2). This was statistically significant: $\chi^{2}=24.27, \mathrm{df}=3, \mathrm{P}<0.001$. The experiment was repeated and leaded to the same conclusion since the orientation of ants under Sativex diet equaled then 70.5 (49.4 - 90.4) angular degrees (not in a table). Such an impact of Sativex on the ants' orientation may be due, for instance, to a lower perception by the ants of their attractive alarm pheromone. Disorientation was also reported in the adverse effects listed in the literature [29,30].

\section{Audacity}

This trait was not impacted by Sativex consumption (Table 2, line 4). Whatever the diet, a few ants came onto the provided unknown experimental apparatus (Figure 2B). They were meanly 2.1 and 2.4 in doing so under normal and Sativex diet respectively, the difference between these two results being not significant $(N=5, T$ $=+11,-4, \mathrm{P}=0.219)$. This may be due at the same time to a decrease of activity (what would reduce the ants' audacity) and to a lesser assessment of danger (what would increase the ants' audacity). If the latter disconnection from reality applies, it may correspond to dissociation reported in the literature [29,30]. 


\section{Tactile (pain) perception}

The ants' tactile perception highly decreased under Sativex consumption (Table 2, lines 5,6 ). While consuming this drug, the ants walked more frankly on the rough paper, less perceiving its uncomfortable character (Figure 2C). Their linear speed was much higher and their angular speed much lower than when living under normal diet, the differences being statistically significant (linear speed: $\chi^{2}=33.07, \mathrm{df}=2, \mathrm{P}<0.001$; angular speed: $\chi^{2}=31.46, \mathrm{df}=2$, $\mathrm{P}<0.001$ ). Such an impact of Sativex on tactile (presumably pain) perception corresponds to the well-documented analgesic effect hoped for this medicine (See Introduction, Efficiency).

\section{Brood caring}

This trait was affected by Sativex consumption (Table 3, line 1). While under normal diet, the ants very quickly perceived the larvae that were removed from the nest, approached them, touched them with their mandibles and antennae (Figure 2D1), and then soon transported them to the nest entrance. When consuming Sativex, they delayed in doing so, being lavish in caring of the larvae (Figure 2D2). Therefore, the numbers of not re-entered larvae in the course of six minutes statistically differed between the two kinds of diet $(\mathrm{N}=6, \mathrm{~T}=21, \mathrm{P}=0.016)$. This may be due to a lowering of perception when consuming Sativex, what would be in the same time in agreement with the ants' lower response to their specific alarm pheromone (see the subsection relative to the ants' orientation). However, this could also be due to the few social relationship problems reported in the literature $[29,30]$. This was examined in the following experiment.

\section{Aggressiveness against nestmates}

Sativex consumption had a rather strong effect on this ethological trait (Table 3, line 2). Under normal diet, two nestmates often stayed aside one another making some antennae contacts and seldom only slightly opening their mandibles. When consuming Sativex, they appeared to avoid each other, and often rather largely opened their mandibles (Figure 2E). The difference of aggressiveness levels presented by ants maintained under the two kinds of diet was highly significant $\left(\chi^{2}=70.53, \mathrm{df}=2, \mathrm{P}<0.001\right)$. Such an impact of Sativex on social relationships may be due to a lower perception of social pheromones (see subsections relative to orientation and to brood caring), as well as to social relationship dysfunction. The latter impairment may correspond to the few psychiatric disorders categorized as paranoia and suicidal ideation mentioned in the literature [29,30]. An impact of Sativex on social relationship problems is not in favor of the use of this medicine.

\section{Escaping ability}

This ethological trait was largely affected by Sativex consumption (Table 3, line 3). While ants under normal diet tried to escape from the enclosure and succeeded in doing so (Figure 2F1), those consuming Sativex less tempted to do so, only 5 ants among 12 succeeding in going out of the enclosure in 12 minutes (Figure 2F2). The difference of escaping ability between ants under the two kinds of diet was significant: $\mathrm{N}=6, \mathrm{~T}=-21, \mathrm{P}=0.016$. This observation agreed with a potential impact of Sativex on a decrease of the individuals' general activity (Table 1) and may correspond to the increase of fatigue mentioned in the manufacturer product monograph [30], which also mentions disorientation, another factor that may explain the ants' lesser escaping ability. It may also be linked to a possible decline in cognition, which trait is examined in the following sub section. Whatever may be the reason, the result of the ants' escaping trial is not in favor of Sativex use.

\section{Cognition}

Sativex largely impacted the ants' cognition (Table 3, line 4). While living under normal diet, six ants among thirty succeeded in crossing the twists and turns path during the 12 experimental minutes. When consuming Sativex, only one ant could do so (Figure $2 \mathrm{G}$ ). Such a difference of behavior between the ants under the two kinds of diet was at the limit of significance due to smallness of the sample (for ants still in front of the difficult path: $\mathrm{N}=5, \mathrm{~T}=$ $+13.5, \mathrm{P}=0.078$; for ants beyond the difficult path: $\mathrm{N}=4, \mathrm{~T}=-10$, $P=0.063$ ). This impact of Sativex may simply result from a lower activity of the ants in the twists and turns path. This is in agreement with the results related in the subsection 'Escaping ability'. A potential impact of Sativex on the ants' cognition, thus on their brain functioning, is examined in the following sub section, even if no negative effect of Sativex on cognition is however reported in the literature [31,32].

\section{Conditioning and memory}

Sativex largely impacted the ants' conditioning acquisition, and therefore their short and middle term memory. Indeed, while under normal diet, the ants acquired a valuable visual conditioning, when consuming Sativex, they acquired no conditioning at all (Table 4). In the Y-apparatus devoted to testing, the ants obviously went randomly to the right or the wrong branch (Figure $2 \mathrm{H}$ ). The difference of conditioning score between the ants under one and the other kind of diet was of course statistically significant $(\mathrm{N}=6, \mathrm{~T}=-21, \mathrm{P}$ $=0.016)$. The ants' middle- and long-term memory could not be ex- 
amined in the course of the present experiment since the ants did not learn. It could only be noted that a notion acquired since a long time (i.e. more than one year) can still be retained by the ants, such as the location of their nest entrance, food sites, cemeteries, and at a lower extend their social odors, since they went on going to these locations and staying in the nest with their nestmates. Memory impairment due to Sativex treatment amounts to a small percentage in the adverse effects list available in the literature $[29,30]$ and in the instructions for use joined to the medicine package. On ants, Sativex appeared to considerably impact memorization, what is not in favor of this drug.

\section{Adaptation (tolerance) to Sativex adverse effects}

After having consumed Sativex during 13 days, the ants went on poorly orienting themselves towards a tied nestmate (Table 5, line 1). Their orientation (70.6 angular degrees) did not statistically differ from that they presented after 2 days of the drug consumption (67.2 angular degrees) $\left(\chi^{2}=0\right)$, but greatly differed from that presented under normal diet (44.8 angular degrees) $\left(\chi^{2}=19.63, \mathrm{df}=3\right.$, $\mathrm{P}<0.001)$. There was thus no adaptation to the adverse effects of Sativex, which persistence all along consumption is not in favor of the use of this medicine.

\section{Habituation to Sativex wanted effects}

No habituation occurred as for the effect of Sativex on the ants' tactile perception (Table 5, line 2). The experiments were made being blind to the previous results, i.e. to the control ones and those obtained after four days of the drug consumption. After 14 days of Sativex consumption, the ants' linear speed on a rough substrate still largely differed from the control one $\left(\chi^{2}=33.07, \mathrm{df}=2, \mathrm{P}<\right.$ 0.001 ), and was similar to that observed after four days of the drug consumption $\left(\chi^{2}=1.94, \mathrm{df}=2,0.30<\mathrm{P}<0.50\right)$. In the same way, after 14 days of Sativex consumption, the ants' tactile (pain) perception was still largely reduced, the ants' angular speed on a rough substrate being far smaller than the control one $\left(\chi^{2}=31.29, \mathrm{df}=\right.$ $2, \mathrm{P}<0.001$ ) and similar to that observed after four days of the drug consumption $\left(\chi^{2}=0.33, \mathrm{df}=1,0.50<\mathrm{P}<0.70\right)$. Such a lack of habituation to the wanted analgesic effect of the drug is strongly in favor of its use.

Also, no habituation (as exemplified by the absence of dose escalation) was reported after 52 weeks of Sativex use to relieve pain [24] as well as in another long-term follow-up where patients suffering from multiple sclerosis even reduced by themselves their self-titrated dose [27].

\section{Dependence on Sativex consumption}

Sativex leaded to a strong dependence on its consumption (Table 5, line 3; Figure 2I). During the experiment, the ants were not very active and often opened their mandibles, what was unusual. In total, 74 ants approached the tube containing Sativex but scarcely (since their consumption of sugar water was largely decreased) consumed its content. During the same time, only 7 ants approached the tube free of Sativex and never consumed its content. These numbers statistically differed from those expected if ants went randomly near each kind of tube $\left(\chi^{2}=7.85, \mathrm{df}=1,0.001\right.$ $<\mathrm{P}<0.01$ ). There was thus an obvious preference for Sativex consumption, what should be taken into account when treating patients with this medicine. However, we did not observe a strong withdrawal syndrome after weaning: in a few hours, the ants recovered, becoming and behaving as when living under normal diet.

In humans, a study reported only symptoms of a mild dependence in $44 \%$ of 25 multiple sclerosis patients who agreed to abruptly interrupt for two weeks their Sativex medication after having been under meanly more than one year of this treatment. Of these patients, 22 (88\%) wanted to re-start their Sativex treatment during or after the two-week interruption [27]. In a comparative study of drug discrimination between Sativex, THC only (a cannabinoid with some abuse potential) and placebo in recreational marijuana users, measured on drug preference scales and on cognitive and motor effects, a dose of 8 sprays of Sativex had somewhat lower effects than that of a comparable quantity of THC only, what suggests that Sativex has a lesser abuse potential than THC alone [35]. Nevertheless, the Sativex manufacturer GW Pharma warns against its use in patients with addiction and drug abuse liability as multiple substance abuse is common [30].

\section{Decrease of the effects of Sativex after weaning}

Numerical and statistical results are given in Table 6 and illustrated in Figure 3. A fresh solution of Sativex having been given to the ants before $t=0 \mathrm{~h}$, two hours after weaning the ants appeared to be still largely affected by the drug, their linear and angular speeds on a rough surface not significantly differing from those presented at $\mathrm{t}=0 \mathrm{~h}$. Four hours after weaning, a decrease of the effect of Sativex on pain perception was observed, the ants' linear speed being not yet significantly lower than that presented at $\mathrm{t}=0 \mathrm{~h}$, but well their angular speed. Six hours after weaning, although linear speed and sinuosity were significantly different from those at $t=$ $0 \mathrm{~h}$, the drug effect remained efficient since these traits were still significantly different from the control ones. From 8 hours after 
weaning, the ants' linear speed on a rough substrate became statistically well different from that presented at $\mathrm{t}=0 \mathrm{~h}$ and 10 hours after weaning, it became not significantly different from the control value. Between 12 and 14 hours after weaning, the effect of Sativex entirely vanished. It should even be noted that fourteen hours after weaning the ants not only became again sensitive to the uncomfortable character of the substrate, as they were expected to be under a normal sugar water diet, but they became even more sensitive since they walked slower than usually ( $P=0.003)$. In fact, the ants were recovering during a few hours and thereafter were again in good health, just like before consuming Sativex (for instance, they eat as usually), what allowed undertaking the study of the impact of ethanol consumption.

Mathematically, the decrease of the effect of the active compounds of Sativex appeared to be best described by a linear function of the running time, the proportion of explained variance $\left(\mathrm{R}^{2}\right)$ being 0.96 when based on the median values of the linear speed and of 0.94 when based on the median values of the angular speed.

These linear functions are for the median linear speed: $y=10.47$ $-0.40 \mathrm{x}$ and for the median angular speed: $\mathrm{y}=111.08+11.02 \mathrm{x}$.

The mean decrease of the linear speed after weaning was 0.4 $\mathrm{mm} / \mathrm{sec}$ per hour, and the mean increase of the angular speed was 10.64 ang. deg./cm per hour.

Figure 3 shows an increase of linear speed between 4 and $6 \mathrm{~h}$ after weaning and its decrease between 6 and $8 \mathrm{~h}$, what could recall the irregularity in the decrease along time of the THC/CBD concentration observed in human blood plasma [36]. However, no obvious irregularity corresponding to the same time periods was observed for the angular speed, and thus, irregularities seen since weaning may perhaps not correspond to a decrease with multiple peaks as the one observed for human plasma.

To summarize, the potent effect of Sativex on tactile (pain) perception began to be less efficient 4 hours after weaning, became obviously less efficient 8 - 10 hours after weaning, and vanished in 12 - 14 hours. Such a strong loss of effect accounts for the development of some dependence, expressed by a preference for a diet containing this medicine (as it has been observed on ants with other drugs [45]). However, no important withdrawal syndrome was observed after weaning.

\section{Impact of ethanol consumption}

This study was conducted to look if some of the effects observed for Sativex were due or influenced by the presence of ethanol in this medicine. If not, the effects observed for Sativex would effectively be induced by the two active cannabinoids (THC and CBD) contained in that medicine.

Note that ethanol was here given in the ants' food and not as a volatile and was thus consumed and digested by the ants. Its effects, if any, differed thus from those of the ethanol contained in and emitted as a volatile by the workers' Dufour gland [46]. Note also that each spray of Sativex contains $50 \mu \mathrm{l}$ of ethanol, and that humans using eight oromucosal sprays per day receive thus $400 \mu$ l of that alcohol per day what is a very small amount which can be neglected comparatively to humans' commonly consumed amounts of alcohol.

\section{Sugar water and meat food consumption, general activity}

Numerical results are given in Table 1 . While consuming ethanol, the ants were slightly more active $(\mathrm{N}=6, \mathrm{~T}=+20, \mathrm{P}=0.031)$, eat a similar amount of meat $(\mathrm{N}=6, \mathrm{~T}=-9,+12, \mathrm{P}=0.422)$, and consumed a similar quantity of sugar water $(\mathrm{N}=6, \mathrm{~T}=+8.5,-12.5$, $\mathrm{P}=0.383$ ) than while under normal diet. Consequently, the effect of Sativex on these three physiological traits (see the corresponding subsection relative to Sativex) is not due to ethanol, but to the impact of the two active cannabinoids contained in the drug.

These results as well as those here below related show that the ants duly recovered in two days after their 17 days of Sativex consumption, what is in agreement with the fact that health problems are rarely observed after Sativex weaning.

\section{Linear and angular speeds}

Ethanol did not impact the ants' linear speed $\left(\chi^{2}=0, P=1\right)$ but slightly increased their angular speed $\left(\chi^{2}=6,97, \mathrm{df}=2,0.02<\mathrm{P}\right.$ $<0.05$ ) (Table 2, lines 1 and 2). Such an effect is the same as that found when studying the ethological activity of the Dufour gland content [46], but here, it appeared with a lower intensity according to the very small amount and the ingested character of the ethanol.

Ethanol somewhat increased the ants' sinuosity and Sativex did not, its two active compounds (THC and CBD) thus somewhat decreasing this sinuosity. In fact, Sativex reduced the ants' foraging behavior (and foraging includes some sinuosity), what is in agreement with the negative impact of the drug on the ants' general activity (Table 1). 


\begin{tabular}{|l|ccc|ccc|ccc|}
\hline \multirow{2}{*}{ Days } & \multicolumn{3}{|c|}{ Normal diet } & \multicolumn{3}{c|}{ Diet with Sativex } & \multicolumn{3}{c|}{ Diet with ethanol } \\
& Activity & Meat & Sugar water & Activity & Meat & Sugar Water & \multicolumn{2}{c|}{ Activity } & Meat \\
Sugar Water
\end{tabular}

Table 1: Effect of Sativex and ethanol on the ants' general activity and food consumption.

During six days, on two colonies, the ants being active, eating meat and drinking sugar water were counted four times and the mean of these eight counts were established (upper part of the table). The mean of these six mean counts was also established (lower part of the table). Sativex decreased the three assessed traits, while ethanol only slightly increased their activity.

\section{Orientation}

Ethanol did not impact the ants' orientation to a tied nestmate (Table 1, line 3; Figure 2A3). While consuming this alcohol, the ants went on soon reacting to the alarm pheromone emitted by a tied nestmate and duly oriented themselves towards it. They did so even somewhat better than when under normal diet, but this difference was not significant $\left(\chi^{2}=2.51, \mathrm{df}=2, \mathrm{P} \sim 0.30\right)$. Consequently, the impact of Sativex on the ants' orientation ability and on their olfactory perception (see the subsection 'Orientation' relative to Sativex) was effectively due to the effect of the two active compounds of the drug.

\section{Audacity}

The audacity of ants consuming ethanol was identical to that of ants living under normal diet (Table 2, line 3; Figure 2B3) $(\mathrm{N}=$ $4, \mathrm{~T}=+3.5,-6.5, \mathrm{P}=0.375$ ). What we concluded about the effect of Sativex on the ants' audacity concerned thus the effect of the two active compounds of the drug.

\section{Tactile (pain) perception}

Ants consuming ethanol went on perceiving the uncomfortable character of the rough substrate but less than when living under normal diet (Figure 2C3). They walked there at a low linear speed, similar to the control one ( 6.0 vs $5.4 \mathrm{~mm} / \mathrm{sec} ; \chi^{2}=1.37, \mathrm{df}=1,0.20$ $<\mathrm{P}<0.30$ ), but with a somewhat lesser angular speed (222 vs 269 ang.deg./cm; $\chi^{2}=12.09, \mathrm{df}=2,0.001<\mathrm{P}<0.01$ ) (Table 2, lines 4, 5). It could thus be concluded that the strong decrease of tactile perception observed for ants consuming Sativex was essentially due to the impact of the two active compounds of this drug, the ethanol diet alone slightly decreasing the ants' sinuosity (see the subsection on tactile perception relative to Sativex, the statistical results). Note that a slight decrease of pain perception caused by ethanol is also known in humans and has even been largely used in the past for treating patients when no analgesic was available.

\section{Brood caring}

The ethanol diet did not affect the ants' behavior towards their

\begin{tabular}{|l|c|c|c|}
\hline Traits & Normal diet & Diet with Sativex & Diet with ethanol \\
\hline Linear speed (mm/sec) & $12.0(10.5-13.3)$ & $11.6(10.4-13.2)$ & $12.0(10.7-12.9)$ \\
Angular speed (ang.deg./cm) & $122(103-129)$ & $118(100-131)$ & $139(118-153)$ \\
Orientation (ang. deg.) & $44.8(27.9-56.0)$ & $67.2(54.5-83.7)$ & $37.9(30.5-53.6)$ \\
Audacity ( $\left.{ }^{\circ}\right)$ & $2.1[1-3]$ & $2.4[1-4]$ & $2.0[1-3]$ \\
Tactile perception & & & \\
Linear speed (mm/sec) & $5.4(4.7-6.5)$ & $9.1(8.0-10.7)$ & $6.0(5.4-6.8)$ \\
Angular speed (ang.deg./cm) & $269(249-310)$ & $159(149-177)$ & $222(211-256)$ \\
\hline
\end{tabular}

Table 2: Effect of Sativex and ethanol on five ethological and physiological traits. Sativex consumption decreased the ants' orientation ability and their tactile (pain) perception, while ethanol somewhat increased their angular speed and somewhat decreased their tactile perception. The table gives the median (and quartiles) or the mean [and extremes] of the obtained values. Photos are shown in figure 2. 
larvae. As when under normal diet, the ants consuming this alcohol very quickly came near the larvae which had been removed from the nest and transported them into the nest (Figure 2D3). There was no statistical difference between the ants consuming or not ethanol as for the numbers of larvae not re-entered over time (Table 3, line $1 ; \mathrm{N}=0$, NS). The observed negative effect of Sativex on the ants' brood caring was thus due to the two active compounds of this drug.

\section{Aggressiveness against nestmates}

The ethanol diet did not change the ants' behavior towards their nestmates. They never aggressed them, but stayed aside them, doing nothing or touching them with their antennae (Figure 2E3). The difference, between ants living under normal diet or under a diet with ethanol, as for their presented levels of aggressiveness during dyadic encountering, was not significant (Table 3 , line $2 ; \chi^{2}$ $=0.93, \mathrm{df}=2,0.30<\mathrm{P}<0.50$ ). The negative impact of Sativex on the ants' social relationships, resulting in an increase of aggressiveness between nestmates, was thus due to the two cannabinoids contained in the drug.

\section{Escaping ability}

This ethological trait was not statistically affected by ethanol consumption (Table 3 , line $3 ; \mathrm{N}=5, \mathrm{P}>0.50$ ). While consuming that alcohol, the ants could escape from the enclosure like while living under normal diet although with some delay (about 4 - 5 minutes delay) (Figure 2F3), what could be due to the slightly larger sinuosity of the ants consuming ethanol, the ants then walking less along the rim of the enclosure and somewhat failing in finding the exit.

\section{Cognition}

This trait was not affected by ethanol consumption (Table 3, line 4; Figure 2G3). While consuming this alcohol, the ants placed in front of twists and turns went inside this difficult path and seven ones succeeded in reaching the zone located beyond the twists and turns. Eight ants were still in front of the difficult path after 12 minutes. The difference in behavior between the ants under ethanol and under normal diet was not significant taking into account the ants remaining in front of the twists and turns $(\mathrm{N}=6, \mathrm{~T}=-11,+10$, $P=0.50$ ), and at the limit of significance taking into account the ants reaching the zone beyond the twists and turns $(\mathrm{N}=4, \mathrm{~T}=10, \mathrm{P}$ $=0.063$ ). Consequently, the impact of Sativex on the ants' cognition (see the sub section on cognition relative to Sativex) is effectively due to the two active compounds of the drug.

\section{Conditioning and memory}

The ants' conditioning acquisition was not affected by ethanol consumption but their middle term memory was somewhat impacted (Table 4, Figure 2H3). Under ethanol diet, the ants quickly acquired conditioning: they already presented a score of $60 \%$ after only 7 training hours and the different conditioning scores they presented did not statistically differ from those of ants under normal diet $(\mathrm{N}=4, \mathrm{~T}=+6.5,-3.5, \mathrm{P}=0.375)$. This was far different from what occurred for ants consuming Sativex as the latter could no acquire conditioning. This incapability of learning under Sativex diet was thus due to the impact of the two cannabinoids contained in the drug. Coming back to ethanol, during their training, the ants seemed not keeping their conditioning: for instance, after 48 training hours, they presented a score of only 55\%. This observation was confirmed when examining the ants' loss of conditioning. As soon as 7 hours after the removal of the cue, the ants consuming ethanol presented a conditioning score of only $45 \%$ : they had thus lost all the acquired conditioning. On the basis of the six scores assessed after the cue removal, it can be affirmed that the ants' memory was effectively affected by ethanol consumption $(\mathrm{N}=6, \mathrm{~T}=-21$, $P=0.016)$. Such an impact of ethanol on the memory is well known in humans: after having drunk some amount of that alcohol, people are less able to remember what occurred just before drinking. The relation between this impact of ethanol on memory and that on pain perception is discussed in the sections 'Discussion' and 'Conclusion'.

Habituation to the effect of ethanol on tactile (pain) perception

There was no habituation to the effect of ethanol on the ants' tactile (pain) perception (Table 5, line 4). After 14 days of that alcohol consumption, the ants still walked on a rough substrate at an angular speed lower than the control one and even slightly lower, although not significantly, than the one presented after 4 days of ethanol consumption $\left(\chi^{2}=3.04\right.$, df $\left.=2,0.20<P<0.30\right)$. Such a result does not modify what was found for Sativex, i.e. there was no habituation to the effect of Sativex. We can thus conclude that there was no habituation to the strong effect on pain perception of the two active compounds of Sativex, or to the very slight effect on pain perception due to the ethanol present in that drug.

\section{Dependence on ethanol consumption}

The ants consuming ethanol did not become dependent on that alcohol (Table 5, last line; Figure 2I3). Indeed, a total of 72 ants 


\begin{tabular}{|c|c|c|c|}
\hline Traits & Normal diet & $\begin{array}{l}\text { Diet with } \\
\text { Sativex }\end{array}$ & $\begin{array}{c}\text { Diet with } \\
\text { ethanol }\end{array}$ \\
\hline \multicolumn{4}{|c|}{ Brood caring: $\mathrm{n}^{\circ}$ of not re-entered larvae after } \\
\hline $1 \mathrm{~min}$ & 8 & 12 & 8 \\
\hline $2 \min$ & 6 & 12 & 6 \\
\hline $3 \mathrm{~min}$ & 4 & 10 & 4 \\
\hline $4 \mathrm{~min}$ & 2 & 10 & 2 \\
\hline $5 \mathrm{~min}$ & 0 & 8 & 0 \\
\hline $6 \mathrm{~min}$ & 0 & 4 & 0 \\
\hline \multicolumn{4}{|c|}{ Aggressiveness: numbers of behavioral levels } \\
\hline 0 & 102 & 21 & 84 \\
\hline 1 & 35 & 27 & 38 \\
\hline 2 & 13 & 52 & 11 \\
\hline 3 & 0 & 0 & 0 \\
\hline 4 & 0 & 0 & 0 \\
\hline Variable 'a' $=(2+3+4) /(0+1)$ & 0.09 & 1.08 & 0.09 \\
\hline \multicolumn{4}{|c|}{ Escaping performance: $\mathrm{n}^{\circ}$ of ants escaped after } \\
\hline $2 \min$ & 2 & 0 & 1 \\
\hline $4 \mathrm{~min}$ & 4 & 0 & 3 \\
\hline $6 \mathrm{~min}$ & 6 & 2 & 5 \\
\hline $8 \mathrm{~min}$ & 6 & 2 & 9 \\
\hline $10 \mathrm{~min}$ & 9 & 3 & 10 \\
\hline $12 \mathrm{~min}$ & 12 & 5 & 12 \\
\hline \multicolumn{4}{|l|}{$\begin{array}{l}\text { Cognition: } n^{\circ} \text { of ants in front of and } \\
\text { beyond the difficult path after }\end{array}$} \\
\hline $2 \min$ & 26 and 0 & 25 and 0 & 23 and 0 \\
\hline $4 \mathrm{~min}$ & 22 and 0 & 22 and 0 & 21 and 0 \\
\hline $6 \mathrm{~min}$ & 16 and 1 & 17 and 0 & 17 and 2 \\
\hline $8 \mathrm{~min}$ & 12 and 3 & 15 and 0 & 14 and 4 \\
\hline $10 \mathrm{~min}$ & 10 and 4 & 13 and 0 & 11 and 5 \\
\hline $12 \mathrm{~min}$ & 9 and 6 & 12 and 0 & 8 and 7 \\
\hline
\end{tabular}

Table 3: Effects of Sativex on four ethological and physiological traits. Sativex impacted the ants' brood caring, aggressiveness against nestmates (thus the social relationships), escaping performance and cognition, while ethanol did not affect these traits. Photos are shown in Figure 2. 


\begin{tabular}{|c|c|c|c|}
\hline Time & $\begin{array}{c}\text { Normal } \\
\text { diet }\end{array}$ & $\begin{array}{l}\text { Diet with Sa- } \\
\text { tivex }\end{array}$ & $\begin{array}{c}\text { Diet with } \\
\text { ethanol }\end{array}$ \\
\hline \multicolumn{4}{|l|}{ Conditioning } \\
\hline 7 hours & $55 \%$ & 9 vs $11 ; 45 \%$ & 12 vs $8 ; 60 \%$ \\
\hline 24 hours & $60 \%$ & 9 vs $11 ; 45 \%$ & 13 vs $7 ; 65 \%$ \\
\hline 31 hours & $60 \%$ & 9 vs $11 ; 45 \%$ & 14 vs $6 ; 70 \%$ \\
\hline 48 hours & $65 \%$ & 9 vs $11 ; 45 \%$ & 11 vs $9 ; 55 \%$ \\
\hline 55 hours & $65 \%$ & 10 vs $10 ; 50 \%$ & 13 vs $7 ; 65 \%$ \\
\hline 72 hours & $70 \%$ & 10 vs $10 ; 50 \%$ & 14 vs $6 ; 70 \%$ \\
\hline \multicolumn{4}{|l|}{ Cue Removal } \\
\hline 7 hours & $65 \%$ & & 9 vs $11 ; 45 \%$ \\
\hline 24 hours & $75 \%$ & & 10 vs $10 ; 50 \%$ \\
\hline 31 hours & $70 \%$ & Cannot be ex- & 10 vs $10 ; 50 \%$ \\
\hline 48 hours & $70 \%$ & & 9 vs $11 ; 45 \%$ \\
\hline 55 hours & $70 \%$ & & 10 vs $10 ; 50 \%$ \\
\hline 72 hours & $70 \%$ & & 10 vs $10 ; 50 \%$ \\
\hline
\end{tabular}

Table 4: Effect of Sativex and ethanol on learning and memory during 72 hours of visual operant conditioning and during a same time period after removal of the cue. The table gives the numbers of correct responses versus the numbers of wrong ones, and consequently the conditioning scores, for ants under Sativex diet and ethanol diet. The conditioning scores of ants under normal diet have previously been obtained on similar colonies of the same species [42]. Sativex impacted the ants' conditioning ability so largely that their memory could not be assessed. Ethanol allowed ants acquiring conditioning but affected their memory, the ants soon losing the momentarily acquired conditioning. Photos are shown in figure 2 .

were counted at the entrance of the tube containing pure sugar water while 48 ants were counted at the entrance of the tube containing the sugared solution of ethanol used all along the present experimental work. This corresponded to $60 \%$ and $40 \%$ of the tested ants respectively. These numbers did not statistically differ from those expected if ants randomly went to the two tubes $\left(\chi^{2}=2.04\right.$, $\mathrm{df}=1,0.10<\mathrm{P}<0.20$ ), nor did the numbers corresponding to only colony A $(0.50<\mathrm{P}<0.70)$ or colony B $(0.20<\mathrm{P}<0.30)$. Significant dependence on ethanol consumption is expected to develop when much larger amounts of ethanol are consumed, and when psychological problems are encountered [45]. According to this result on the potential dependence on ethanol consumption, it can be stated that the observed strong dependence on Sativex consumption was due to the two cannabinoids of the drug (Table 5, 6 and figure 2).

\section{Decrease of the effect of ethanol after weaning}

Numerical results are given in Table 7 and illustrated in Figure 3. Only the ants' angular speed on a rough substrate could be used since their linear speed on such a substrate was similar to the control one (Table 2). Note also that the low amount of ethanol corresponding to that present in the Sativex medicine accounted for the fact that the ants' sinuosity on a rough substrate started at a higher value than that observed under a Sativex diet.

During the first four hours after weaning, the consumed small amount of ethanol kept at full strength its effect on pain perception. Six to 8 hours after weaning, pain perception increased but not yet significantly (after 8 hours the ants' sinuosity had changed only from 178 to 211 ang.deg./cm). After that, the effect of ethanol on pain perception vanished, becoming, from $10 \mathrm{~h}$ after weaning, statistically different from that at $t=0(P<0.001)$. Twelve hours after weaning, the ethanol solution lost all its effects, the ants' sinuosity becoming similar to the control one (265 vs 269 ang. deg./ $\mathrm{cm})$. The small amount of ethanol contained in the Sativex medicine lost its effect in about 10 hours, via an initial time period of 4 - 5 hours without any significant change. Such a slow loss of effect is in agreement with the non-development of a dependence on the consumption of a small amount of ethanol, e.g. [45]. Let us recall that the amount of ethanol consumed by humans while using Sativex is very small: they use about eight sprays of Sativex per day, and doing so, consume only $400 \mu \mathrm{l}$ of ethanol per day, what should not induce dependence.

The kinetics of the decrease of the effect of the small amount of ethanol contained in the Sativex medicine agreed more with a 


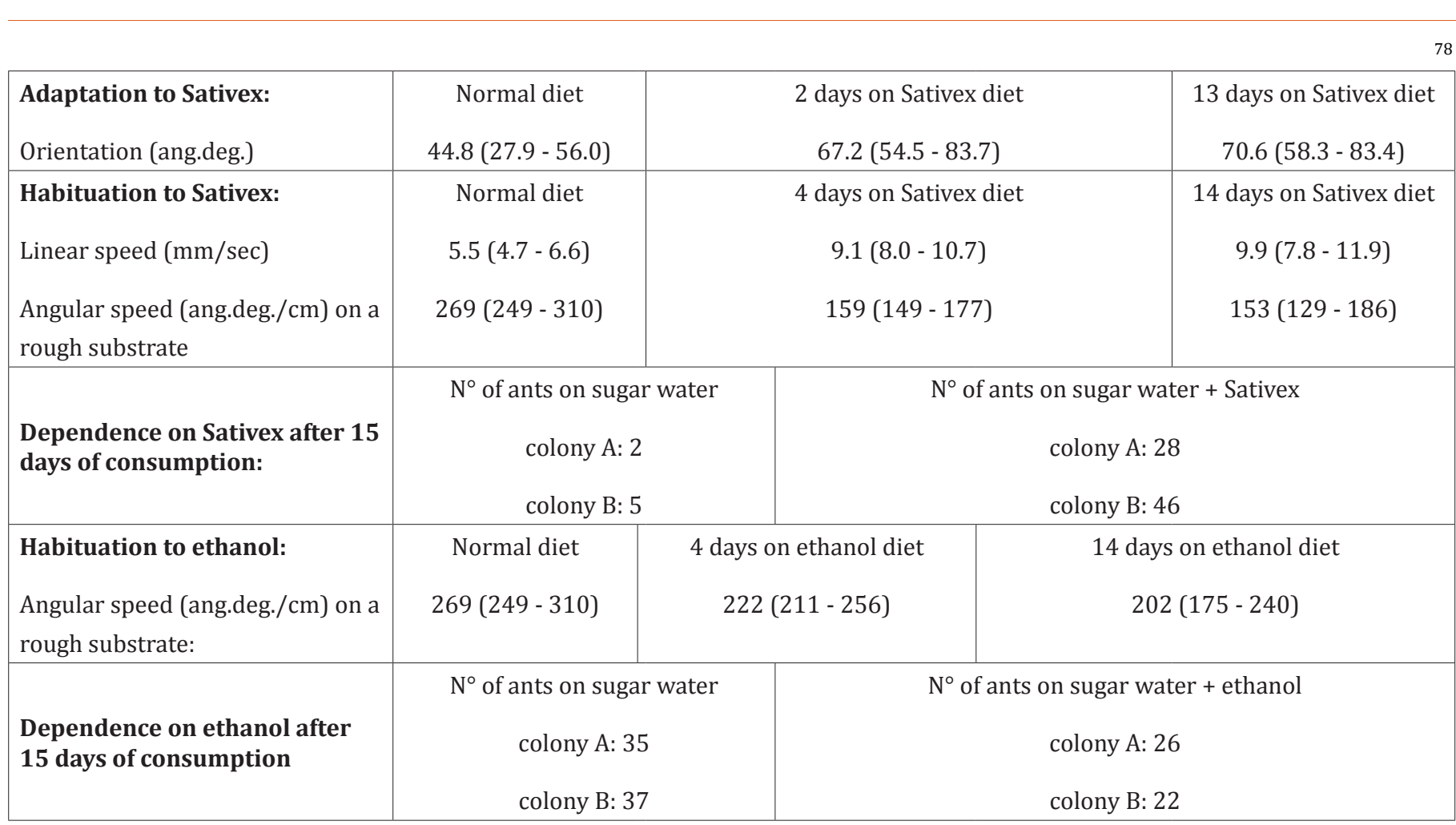

Table 5: Adaptation to adverse effects of Sativex, habituation to its wanted effects, and potential dependence on its consumption. Habituation to the slight effect of ethanol, and potential dependence on its consumption. No adaptation and no habituation occurred for Sativex consumption, but a strong dependence developed. No habituation and no dependence were observed with ethanol consumption. Photos of the experience relative to dependence are shown in Figure 2. Definitions of adaptation, habituation and dependence are given in the text.

\begin{tabular}{|l|c|c|c|c|c|c|}
\hline & \multicolumn{2}{|c|}{ Linear speed on a rough substrate } & \multicolumn{3}{c|}{ Angular speed on a rough substrate } \\
\hline Time & Value (mm/sec) & P, vs t = & P, vs control & Value (ang.deg./cm) & P, vs t = 0 & P, vs control \\
\hline $\mathrm{t}=0$ & $10.3(9.4-11.6)$ & & & $122(107-141)$ & & \\
\hline Weaning & & & & & & \\
\hline $2 \mathrm{~h}$ & $9.5(8.2-10.6)$ & 0.3600 & $<0.001$ & $107(100-121)$ & 0.0686 & $<0.001$ \\
\hline $4 \mathrm{~h}$ & $85(7.4-10.4)$ & 0.0860 & $<0.001$ & $172(150-184)$ & $<0.001$ & $<0.001$ \\
\hline $6 \mathrm{~h}$ & $9.0(7.7-9.9)$ & 0.0210 & $<0.001$ & $174(155-196)$ & $<0.001$ & $<0.001$ \\
\hline $8 \mathrm{~h}$ & $7.4(6.5-8.2)$ & $<0.001$ & 0.0040 & $205(168-248)$ & $<0.001$ & 0.0083 \\
\hline $10 \mathrm{~h}$ & $6.5(5.7-7.1)$ & $<0.001$ & 0.0862 & $223(187-249)$ & $<0.001$ & 0.0114 \\
\hline $12 \mathrm{~h}$ & $5.8(4.7-6.7)$ & $<0.001$ & 0.7709 & $232(205-265)$ & $<0.001$ & 0.0218 \\
\hline $14 \mathrm{~h}$ & $4.5(3.9-5.4)$ & $<0.001$ & 0.0030 & $271(250-320)$ & $<0.001$ & 0.5814 \\
\hline Control & $5.5(4.7-6.6)$ & & & $269(244-310)$ & & \\
\hline
\end{tabular}

Table 6: Decrease of the effect of Sativex on tactile (pain) perception after its consumption was stopped. Sativex appeared to soon lose its effect, becoming not efficient at about 10 hours after weaning. Such a quick decrease leaded to dependence on its consumption. Figure 3 illustrates the present numerical results. 

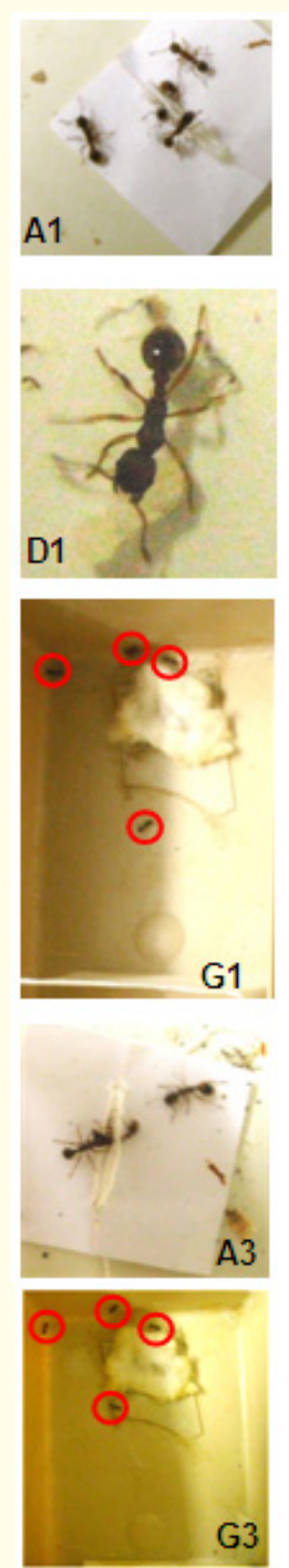
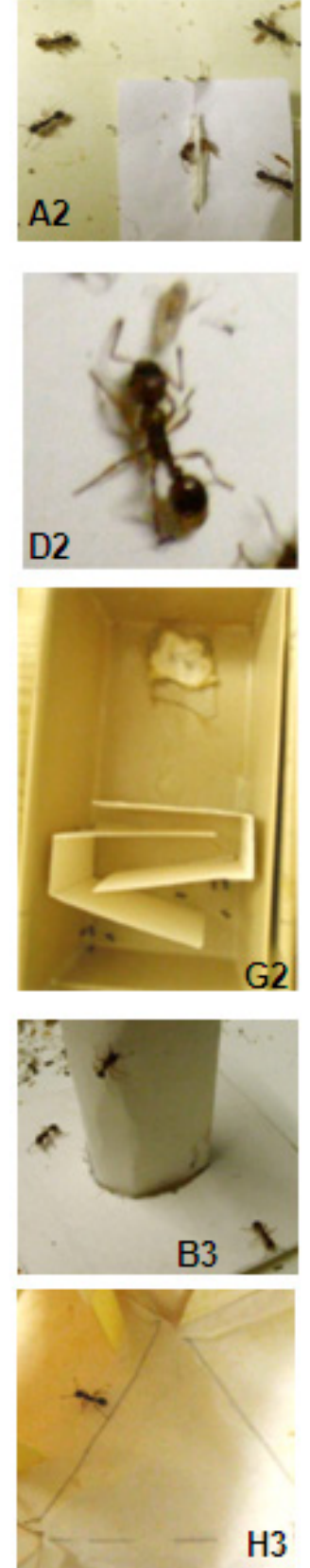
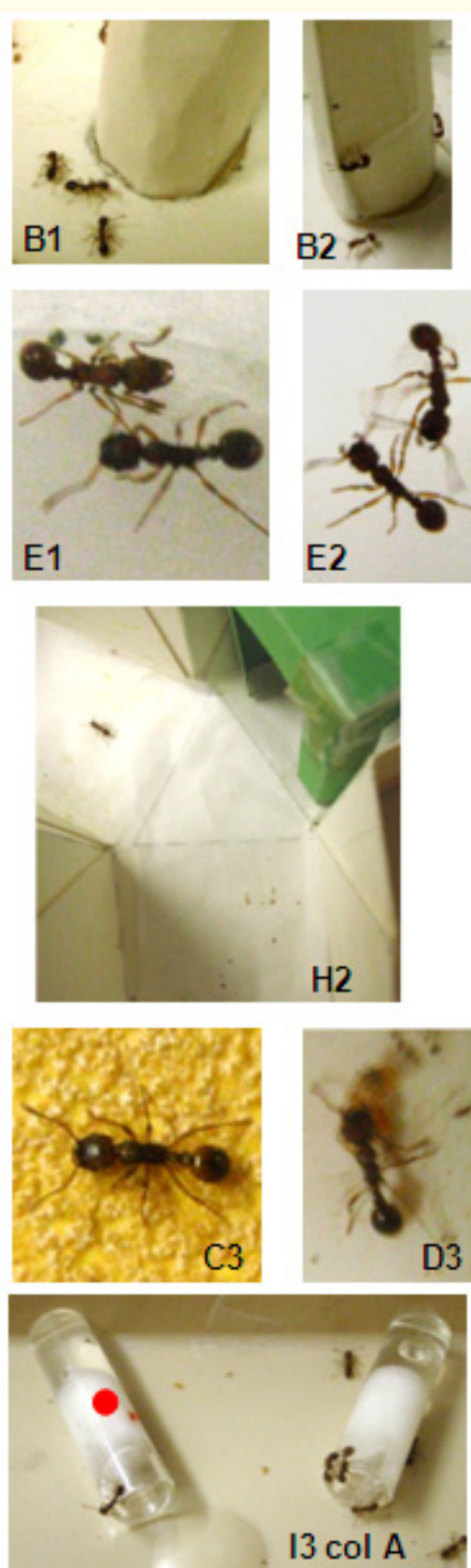
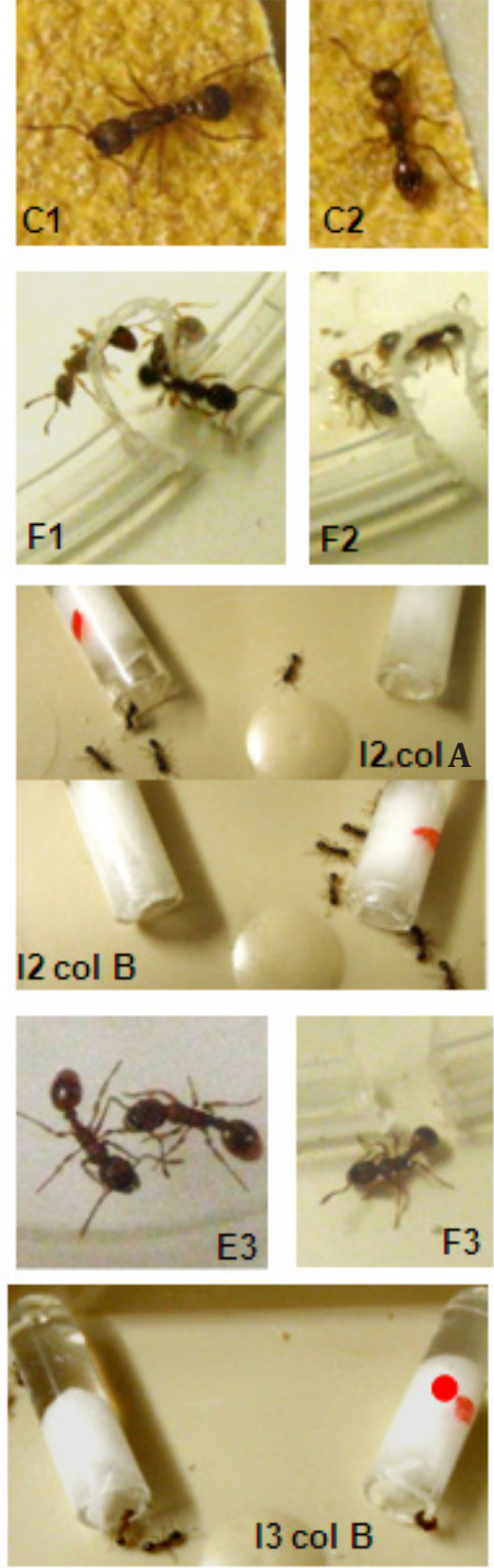

Figure 2: Ants under 1: normal diet, 2: Sativex diet, 3: ethanol diet. A: ants moving towards a tied nestmate, and doing so poorly when under Sativex diet. B: ants coming onto an unknown risky apparatus. C: ants walking on a rough substrate, with difficulty when under normal diet and frankly, less perceiving the uncomfortable character of the substrate, when under Sativex diet. D: an ant taking care of a larva when under a normal diet, but not when consuming Sativex. E: two nestmates staying aside one another, quietly when not consuming Sativex and aggressively (opening their mandibles) when consuming this medicine. F: ants in an enclosure provided with a notch: under normal diet, they succeeded in escaping; under Sativex consumption, they failed to do so. G: four ants under normal diet and no one under Sativex diet having reached the area lying beyond a difficult path. H2: an ant under Sativex diet trained to a hollow green cube giving the wrong response when tested in a Y-apparatus having such a cube in one of its branch. I2: ants under Sativex diet choosing the tube (with a red dot) containing the drug, presenting thus a dependence on this medicine. A3, B3, C3, D3, E3, F3, G3, H3: ants under ethanol diet (the photos show successively: orientation, audacity, tactile (pain) perception, brood caring, aggressiveness against nestmates, escaping ability, cognition, conditioning ability) presenting no behavioral difference in comparison with ants living under normal diet, except some slight decrease of tactile perception (C3). I3: ants presenting no dependence on ethanol (red point) consumption. 


\begin{tabular}{|l|c|c|c|}
\hline \multirow{2}{*}{ Time } & \multicolumn{3}{|c|}{ Angular speed on a rough substrate } \\
\cline { 2 - 4 } & Value (ang.deg./cm) & P, vst $=\mathbf{0}$ & P, vs control \\
\hline $\mathrm{t}=0$ & $178(166-203)$ & & \\
\hline Weaning & & & \\
\hline 2h & $185(164-206)$ & 0.91 & $<0.001$ \\
\hline $4 \mathrm{~h}$ & $183(165-208)$ & 0.81 & $<0.001$ \\
\hline $6 \mathrm{~h}$ & $203(186-231)$ & 0.47 & 0.012 \\
\hline $8 \mathrm{~h}$ & $211(192-248)$ & 0.25 & 0.114 \\
\hline $10 \mathrm{~h}$ & $241(210-274)$ & $<0.001$ & 0.129 \\
\hline $12 \mathrm{~h}$ & $265(237-297)$ & $<0.001$ & 0.93 \\
\hline Control & $269(244-310)$ & & \\
\hline
\end{tabular}

Table 7: Decrease of the effect of the ethanol contained in the Sativex medicine on tactile (pain) perception after its consumption was stopped. Details are given in the text. Briefly, the effect of the small amount of ethanol contained in Sativex slowly decreased, after an initial period without a change, in about eleven hours, what accounted for the absence of dependence on this small amount of ethanol.

The results are graphically shown in Figure 3.
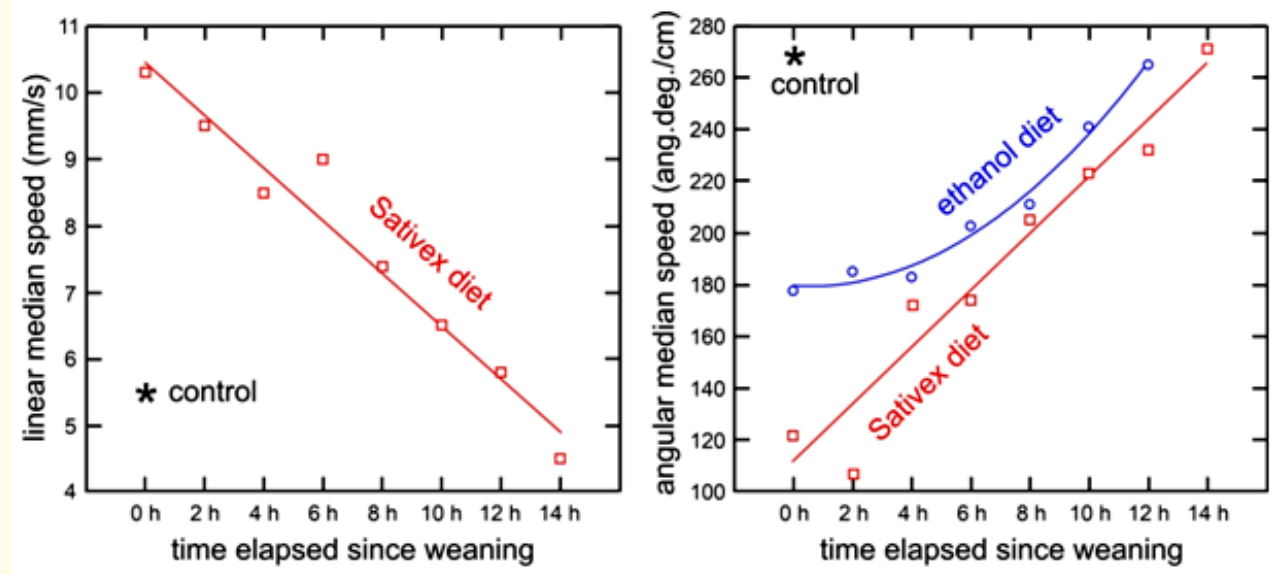

Figure 3: Decrease of the effect of Sativex, and of the small amount of ethanol contained in it, on the ants' tactile (pain) perception. Sativex rapidly lost its effect in about 10 hours; ethanol lost its effect more slowly after an initial period of unchanged effect. This explains the development of a dependence on Sativex consumption. Numerical and statistical results are given in Tables 6 and 7, and details can be found in the text.

polynomial function of second degree $\left(\mathrm{R}^{2}=0.99\right)$ than with a linear function $\left(\mathrm{R}^{2}=0.90\right)$.

For the median angular speed, this function was: $y=179.62-$ $0.73 x+0.66 x^{2}$

Such a non-linear function describes the best a first insignifi- cant decrease of the effect during the first 4 hours after weaning, followed by a progressive increase of the loss of the effect (translated by an increase of the ants' sinuosity), what allowed leading to no dependence [45]. The change of angular speed over the decrease of the effect of ethanol on pain perception meanly equaled 7.25 ang. deg./cm per hour. 


\section{Discussion}

For practitioners, reducing pain perception without using addictive drugs is a challenge. Recently, cannabis-based medicines have been investigated for their potential medicinal effect on pain perception. Sativex is such a novel medicine, and we here examined its ethological and physiological effects on ants. Of course, it is inappropriate to search after beneficial effects of Sativex for ants, as this medicine is intended for caring diseases specific to vertebrates. However, Sativex was found to reduce tactile perception in ants as measured through their locomotion on a rough substrate. Taken into account the insignificant effect of ethanol on the traits examined on ants, we also found that the two cannabinoids contained in the Sativex medicine decreased the ants' general activity, food consumption, foraging activity, orientation ability, social relationships, escaping ability, cognition, learning and memory. No adaptation to these adverse effects occurred, but also no habituation for the impact of Sativex on pain perception.

We showed that Sativex began to be less efficient as soon as four hours after the end of its consumption by the ants and became clearly little efficient 8 - 10 hours after its consumption, what accounted for the development of dependence.

Hereunder, we report what is known from literature about the beneficial and the adverse effects of Sativex and compare again this information to what was found in the present study on ants, we recall the effects the ethanol contained in Sativex, and we conclude.

\section{Beneficial effects of Sativex: Literature and present study on} ants

Used with significant success for reducing spasticity $[14,16]$, Sativex was shown to efficiently reduce related pain [21,22]. It also reduced pain associated to rheumatoid arthritis [23] or characterized by allodynia [24] as well as chronic pain in advanced cancer patients [25]. We here show on ants through their tactile perception that Sativex could effectively reduce pain perception and that no habituation occurred as for this beneficial effect.

Multiple sclerosis patients treated by Sativex and having voluntarily stopped this treatment for experimentation purpose thereafter resumed again their successful Sativex treatment, what demonstrates that this medicine was beneficial [27]. In this way, dependence cannot be perceived as an adverse effect, but express a beneficial effect of this medicine. Contrary to what human beings experience when smoking cannabis, Sativex do not lead to significant addiction (i.e. abuse) because being administered as a mouth spray it delivers less THC in blood, at a slower rate and with a concentration more slowly decreasing over time than when smoking cannabis [36,38]. Dependence on Sativex, expressed by a preference for its consumption, was also shown in ants. This drug became less efficient four hours after the ants stopped consuming it, and no longer efficient ten hours after weaning, the rapidity of the decrease of the effect accounting for the observed dependence.

Sativex is thus beneficial, but it has adverse side effects.

\section{Adverse effects of Sativex}

Let us recall (see the Introduction section) that potential harmful effects of Sativex on humans are reported, the most frequent ones being tiredness, sleepiness, nutrition disorders, less food consumption and weight loss, the last impairments also observed in toxicology studies on laboratory mammals $[27,30]$. These impairments correspond to the decrease of general activity and meat consumption observed in ants under a Sativex diet.

Disorientation and dissociation are also reported in humans $[29,30]$ and may correspond to respectively orientation and escaping ability impairments shown in ants under Sativex diet.

Although social relationships impairments such as paranoia [29] and suicidal ideation [33] were found in no more than $0.5 \%$ of the adverse effects, Russo et al. warned that attention should be paid for early detecting any uncommon neurobehavioral side effect [32]. Some social relationship impairments caused by Sativex were also observed in ants, such as neglecting brood care and exhibiting aggressiveness against nestmates.

Memory impairment is reported in humans where it is due to the reducing effect of THC on the load-dependent response, which increases with the working memory load [47]. A total impairment of learning and memory abilities was found in ants under Sativex diet, what appears to be the worst adverse effect observed on these insects.

No cognitive and mood problems were observed in patients treated with Sativex [31]. Similarly, in two other studies [32,34], Sativex appeared to not significantly impact patients' cognition and 
behavior. However, cognitive motor function deficits and reaction speed impairments were revealed in stop trial tests on THC users (marijuana smokers) [48,49], with substantial impacts on driving skills from a THC blood concentration of 2 - $5 \mathrm{ng} / \mathrm{mL}$ [50] whereas the THC released in their blood may amount to $150 \mathrm{ng} / \mathrm{L}$ within 9 minutes [38]. In comparison, a single dose of 8 Sativex oromucosal sprays is much safer, with a THC concentration in plasma reaching a maximum of $5.4 \mathrm{ng} / \mathrm{mL}$ after $1 \mathrm{~h}$ [38]. The product characteristics published by the Sativex manufacturer nevertheless warns against the danger of driving or operating machinery or making hazardous activity when under treatment [30]. Some cognition impairment was also observed in ants consuming Sativex.

On the whole, for clinical use, the benefits of Sativex seem to overpass its potential adverse effects.

\section{Impact of ethanol contained in Sativex}

The amount of ethanol contained in Sativex is very small. On ants, it had no adverse effect and did not lead to dependence. The significant effects due to Sativex are thus due to its two cannabinoids. Nevertheless, the ethanol present in Sativex appeared to decrease the ants' pain perception and their short-term memory, two effects that may be linked. Indeed, pain is intensely perceived because the brain sums what is perceived all along a time period. Impairment (decrease) of memory allows thus reducing pain perception.

\section{Conclusion}

Sativex obviously helps treating persons for diseases where the endocannabinoid system is involved and by releasing them from pain. Clinical studies and the present work on ants used as a model show that this medicine leads to no habituation to this beneficial effect. However, several harmful side effects are reported in the literature and were also found in the present experimental work on ants. No adaptation to these adverse effects occurred. Consequently, we advise reserving the use of Sativex to patients having severe pain unalleviated by e.g. opioids. We also recommend paying attention to patients treated with Sativex, by regularly controlling their food intake, social relationships, cognition, memory and mental and orientation problems which may present a danger when risky activities such as car driving are concerned.

\section{Conflict of Interest}

We affirm having no conflict of interest concerning the use of Sativex ${ }^{\circledR}$.

\section{Bibliography}

1. Cammaerts MC., et al. "Some physiological and ethological effects of nicotine; studies on the ant Myrmica sabuleti as a biological model". International Journal of Biology 6 (2014): 64-81.

2. Cammaerts MC and Cammaerts R. "Safety of glucosamine, examined on ants as models". MOJ Biology and Medicine 3.4 (2018): 132-142.

3. Cammaerts MC and Cammaerts R. "Safety of meloxicam compared to that of diclofenac, using ants as models". Acta Scientific Pharmaceutical Sciences 3.4 (2019): 45-58

4. Wehner R and Walter G. "Biologie et physiologie animales". Eds. De Boek Université, Thieme Verlag, Paris, Bruxelles (1999): 844.

5. Søvik E and Barron AB. "Invertebrate models in addiction research". Brain Behavior and Evolution 82 (2013): 153-165.

6. Andre RG., et al. "Insect Models for Biomedical Research". In: Woodhead AD, editor. Nonmammalian Animal Models for Biomedical Research. Boca Raton, FL: CRC Press (1989).

7. Passera L and Aron S. "Les fourmis: comportement, organisation sociale et évolution". Les Presses Scientifiques du CNRC, Ottawa, Canada 2005): 480.

8. Cammaerts MC and Cammaerts D. "Comparative outlook over three Myrmica species' biotopes and foragers' know-how". Biologia 69 (2014): 1051-1058.

9. Cammaerts MC and Cammaerts R. "Ants' numerosity ability defined in nine studies". Journal of Biology and Life Sciences 11.1 (2020): 121-142.

10. Russo E and Guy GW. "A tale of two cannabinoids: the therapeutic rationale for combining tetrahydrocannabinol and cannabidiol". Medical Hypotheses 66 (2006): 234-246.

11. Syed YY., et al. "Delta-9-Tetrahydrocannabinol/Cannabidiol $\left(\right.$ Sativex $^{\circledR}$ ): A review of its use in patients with moderate to severe spasticity due to multiple sclerosis". Drugs 74 (2014): 563-578.

12. Boyaji S., et al. "The role of cannabidiol (CBD) in chronic pain management: An assessment of current evidence". Current Pain and Headache Reports 24 (2020): 4.

13. Karschner EL., et al. "Subjective and physiological effects after controlled Sativex and oral THC administration". Clinical and Pharmacological Therapy 89.3 (2011): 400-407. 
14. Collin C., et al. "Randomized controlled trial of cannabis-based medicine in spasticity caused by multiple sclerosis". European Journal of Neurology 14.3 (2007): 290-296.

15. Collin C., et al. "A double-blind, randomized, placebo-controlled, parallel-group study of Sativex, in subjects with symptoms of spasticity due to multiple sclerosis". Neurological Research 32.5 (2010): 451-459.

16. Nottcut W., et al. "A placebo-controlled, parallel-group, randomized withdrawal study of subjects with symptoms of spasticity due to multiple sclerosis who are receiving long-term Sativex $^{\circledR}$ (nabiximols)”. Multiple Sclerosis Journal 18.2 (2012): 219-228.

17. González RA. "A review of the effects of baclofen and THC:CBD oromucosal spray on spasticity-related walking impairment in multiple sclerosis". Expert Review of Neurotherapeutics 18.10 (2018): 785-791.

18. Hilliard A., et al. "Evaluation of the effects of Sativex (THC BDS: CBD BDS) on inhibition of spasticity in a chronic relapsing experimental allergic autoimmune encephalomyelitis: A model of multiple sclerosis". ISRN Neurology (2012).

19. Novotna A., et al. "A randomized, double-blind, placebo-controlled, parallel-group, enriched-design study of nabiximols (Sativex ${ }^{\circledR}$ ), as add-on therapy, in subjects with refractory spasticity caused due to multiple sclerosis". European Journal of Neurology 18.9 (2011): 1122-1131.

20. Flachenecker P., et al. "Nabiximols (THC/CBD oromucosal spray, Sativex ${ }^{\circledR}$ ) in clinical practice - results of a multicenter, non-interventional study (MOVE 2) in patients with multiple sclerosis spasticity". European Neurology 71 (2014): 271-279.

21. Russo M., et al. "Evaluating Sativex ${ }^{\circledR}$ in neuropathic pain management: A clinical and neurophysiological assessment in multiple sclerosis". Pain Medicine 17.6 (2016): 1145-1154.

22. Markova J., et al. "Sativex ${ }^{\circledR}$ as add-on therapy vs. further optimized first-line antispastics (SAVANT) in resistant multiple sclerosis spasticity: a double-blind, placebo-controlled randomized clinical trial". International Journal of Neuroscience 129.2 (2019): 119-128.

23. Blake DR., et al. "Preliminary assessment of the efficacy, tolerability and safety of a cannabis-based medicine (Sativex) in the treatment of pain caused by rheumatoid arthritis". Rheumatology 45 (2006): 50-52.
24. Nurmikko MG., et al. "Sativex successfully treats neuropathic pain characterized by allodynia: a randomized double-blind, placebo-controlled clinical trial". Pain 133.1-3 (2007): 210220.

25. Lichtman AH., et al. "Results of a double-blind, randomized, placebo-controlled study of nabiximols oromucosal spray as an adjunctive therapy in advanced cancer patients with chronic uncontrolled pain". Journal of Pain and Symptom Management 55.2 (2018): 179-188.e1.

26. Russo M. et al. "Sativex in the management of multiple sclerosis-related spasticity: role of corticospinal modulation". Neural Plasticity (2015).

27. Wade DT., et al. "Long-term use of a cannabis-based medicine in the treatment of spasticity and other symptoms in multiple sclerosis". Multiple Sclerosis 12 (2006): 639-645.

28. Constantinescu C., et al. "Long term open label treatment with Sativex ${ }^{\circledR}$ in patients with multiple sclerosis and neuropathic pain". European Journal of Pain 10.S1 (2006): S117c-S118.

29. Robson P. "Abuse potential and psychoactive effects of $\delta$-9tetrahydrocannabinol and cannabidiol oromucosal spray (Sativex), a new cannabinoid medicine" Expert Opinion on Drug Safety 10.5 (2011): 675-685.

30. GW Pharma Ltd. "Product monograph including patient medication information on Sativex, buccal spray antispastic". Sovereign House, Histon, Cambridge, UK (2019).

31. Vachová M., et al. "A multicentre, double-blind, randomised, parallel-group, placebo-controlled study of effect of long-term Sative ${ }^{\circledR}$ treatment on cognition and mood of patients with spasticity due to multiple sclerosis". Journal of Multiple Sclerosis 1.2 (2014): 122.

32. Russo M., et al. "Should we care about sativex-induced neurobehavioral effects? A 6-month follow-up study". European Review for Medical and Pharmaceutical Sciences 20 (2016): 3127-3133.

33. Russo M., et al. "Sativex-induced neurobehavioral effects: causal or concausal? A practical advice!". DARU Journal of Pharmaceutical Sciences 23.1 (2015): 25.

34. López-Sendón Merono JL., et al. "A double-blind, randomized, cross-over, placebo-controlled, pilot trial with Sativex in Huntington's disease". Journal of Neurology 263 (2016): 13901400. 
35. Schoedel KA., et al. "Abuse potential of nabiximols oromucosal spray compared with dronabinol and placebo in recreational marijuana users". European Neuropsychopharmacology 20 (2010) 3: S587.

36. Scott CG., et al. "A phase I study to assess the single and multiple dose pharmacokinetics of THC/CBD oromucosal spray". European Journal of Clinical Pharmacology. 69 (2013): 11351147.

37. McGilveray IJ. "Pharmacokinetics of cannabinoids". Pain Research and Management 10 (2005): 15A-22A.

38. Huestis MA. "Human cannabinoid pharmacokinetics". Chemistry and Biodiversity 4.8 (2007): 1770-1804.

39. Siegel S and Castellan NJ. "Nonparametric statistics for the behavioural sciences". McGraw-Hill Book Company, Singapore (1988): 396.

40. Cammaerts MC., et al. "An easy and cheap software-based method to assess two-dimensional trajectories parameter". Belgian Journal of Zoology 142 (2012): 145-151.

41. Cammaerts MC. "Colour vision in the ant Myrmica sabuleti Meinert, 1861 (Hymenoptera : Formicidae)". Myrmecological News 10 (2007): 41-50.

42. Cammaerts MC., et al. "Collective operant conditioning and circadian rhythms in the ant Myrmica sabuleti (Hymenoptera, Formicidae)". Bulletin de la Société Royale Belge d'Entomologie 147 (2011): 142-154.

43. Zar JH. "Biostatistical analysis". Prentice Hall, NJ, USA, $4^{\text {th }}$ edition (1999).

44. McDonald JH. "Handbook of biological statistics". Sparky House Publishing (2014), Baltimore, Maryland, USA, $3^{\text {rd }}$ ed (2014).

45. Cammaerts MC. "Physical dependence on a substance occurs when the effect of this substance rapidly decreases after withdrawal". JSM Anatomy and Physiology 3.1 (2018): 1017.

46. Cammaerts-Tricot MC. et al. "Dufour's gland secretion of Myrmica rubra: chemical, electrophysiological and ethological studies". Journal of Insect Physiology 22 (1976): 927-932

47. Bossong MG., et al. "Effects of $\Delta 9$-tetrahydrocannabinol on human working memory function". Biological Psychiatry 71 (2012): 693-699.

48. Ramaekers JG., et al. "High-potency marijuana impairs executive function and inhibitory motor control". Neuropsychopharmacology. 31 (2006): 2296-2303.

49. Prashad S and Filbey FM. "Cognitive motor deficits in cannabis users". Current Opinion in Behavioral Sciences 13 (2017): 1-7.
50. Hartman RL and Huestis MA. "Cannabis effects on driving skills". Clinical Chemistry 59.3 (2013): 478-492.

\section{Assets from publication with us}

- Prompt Acknowledgement after receiving the article

- Thorough Double blinded peer review

- Rapid Publication

- Issue of Publication Certificate

- High visibility of your Published work

Website: www.actascientific.com/

Submit Article: www.actascientific.com/submission.php Email us: editor@actascientific.com

Contact us: +919182824667 